\title{
Os programas de integridade pública no Brasil: indicadores e desafios
}

\author{
ROdRIgo TAVARES DE SOUZA BARRETO ${ }^{1}$ \\ JAMES BATISTA VIEIRA ${ }^{1}$ \\ ${ }^{1}$ Universidade Federal da Paraíba (UFPB), JoÃo Pessoa - PB, Brasil
}

\section{Resumo}

Este artigo descreve os programas de integridade implementados pela administração pública direta brasileira, com o objetivo de comparar suas práticas com o regime internacional anticorrupção. A pesquisa analisou 12 programas de integridade pública criados por governos federal, estadual e municipal. Cada um deles foi analisado por meio de 36 indicadores, agrupados em 9 diretrizes, de acordo com as práticas previstas no regime nacional e internacional anticorrupção. Os resultados indicam que, apesar de ainda existir um número reduzido de programas, em média $70 \%$ das práticas previstas nesses regimes são observadas ao menos parcialmente. As evidências apontam que os principais desafios para o aperfeiçoamento desses programas são a adoção de verificações prévias, a combinação adequada entre os canais de denúncia e as investigações internas, bem como a promoção de capacidades institucionais. O estudo descreve as práticas adotadas pelos programas de integridade pública por meio de um conjunto de indicadores que podem ser comparados e replicados em futuras pesquisas sobre o tema.

Palavras-chave: Integridade pública. Corrupção. Compliance. Anticorrupção. Governança pública.

\section{Public integrity programs in Brazil: indicators and challenges}

\begin{abstract}
This article describes the public integrity programs implemented by the Brazilian direct public administration, to compare their practices with the international anti-corruption regime. The study analyzed 12 public integrity programs implemented by federal, state, and municipal governments. Following the practices provided for in the national and international anti-corruption regime, each program was analyzed using 36 indicators, grouped into 9 guidelines. The results indicate that, although there is still a small number of programs, on average, $70 \%$ of the practices provided for in these regimes are observed at least partially. The evidence points out that the main challenges for improving these programs are the adoption of prior checks, the appropriate combination between the channels of complaints and internal investigations, and the promotion of institutional capacities. The study describes the practices that public integrity programs adopt through a set of indicators that can be compared and replicated in future research on the topic.
\end{abstract}

Keywords: Public integrity. Corruption. Compliance. Anti-corruption. Public governance.

\section{El panorama de la integridad pública en Brasil: indicadores y desafíos}

\section{Resumen}

Este artículo describe los programas de integridad implementados por la administración pública directa brasileña, con el objetivo de comparar sus prácticas con el régimen internacional anticorrupción. La investigación analizó 12 programas de integridad pública implementados por el gobierno federal, estatal y municipal. De acuerdo con las prácticas previstas en el régimen anticorrupción nacional e internacional, cada programa se analizó utilizando 36 indicadores, agrupados en 9 pautas. Los resultados indican que, aunque todavía hay un pequeño número de programas, en promedio, el $70 \%$ de las prácticas previstas en estos regímenes se observa al menos parcialmente. La evidencia señala que los principales desafíos para la mejora de estos programas son la adopción de controles previos, la combinación apropiada entre los canales de denuncia e investigaciones internas y la promoción de capacidades institucionales. El estudio describe las prácticas que adoptan los programas de integridad pública a través de un conjunto de indicadores que se pueden comparar y replicar en futuras investigaciones sobre el tema.

Palabras clave: Integridad pública. Corrupción. Compliance. Anticorrupción. Gobernanza pública. 


\section{INTRODUÇÃO}

Os anos recentes reservaram à administração pública brasileira um crescente interesse na gestão da integridade. Seu ápice foi alcançado após os escândalos de corrupção que tiveram como principal efeito a aprovação da Lei Anticorrupção - Lei $n^{\circ}$ 12.846/2013 (Coelho, 2016; Veríssimo, 2017). Essa norma, baseada no referencial internacional anticorrupção, mudou o paradigma ao reconhecer que, tomadas isoladamente, as medidas punitivas tradicionais são ineficazes, devendo ser associadas a mecanismos preventivos que fortaleçam a conformidade com os princípios éticos, as melhores práticas de gestão e as normas legais (Manacorda, 2014).

Os programas de integridade são o conjunto estruturado de ações, realizadas nas organizações públicas, sociais ou privadas, voltadas a prevenção, deteç̧ão, punição e remediação de fraudes e atos de corrupção (Tribunal de Contas da União [TCU], 2014). Sua adoção promove uma cultura de integridade que, segundo a Controladoria-Geral da União (CGU, 2017), é um requisito para elevar a confiança da sociedade nas instituições públicas. Além disso, segundo a Organização para a Cooperação e p Desenvolvimento Econômico (OCDE, 2018), a prevenção à corrupção no setor público é essencial para o desenvolvimento do Estado, pois assegura um ambiente propício aos investimentos públicos e privados.

Inserida na estrutura de governança corporativa, a política de integridade é um processo contínuo que envolve identificação das exigências éticas, administrativas e legais, análise e mitigação dos riscos de não conformidade e adoção das medidas preventivas e corretivas necessárias (CGU, 2015b). A prevenção e a detecção de irregularidades devem integrar o dia a dia das organizações públicas e ser parte obrigatória para análise das políticas públicas, um dos componentes do processo de tomada de decisões dos agentes públicos (CGU, 2015b).

Não existe um modelo único para a implementação dos programas de integridade, porém há um marco legal nacional e internacional, assim como padrões gerenciais vigentes amplamente reconhecidos. O principal marco é a Convenção das Nações Unidas contra a Corrupção, que reconhece internacionalmente a importância da adoção de medidas preventivas (Vlassis, 2014). Entretanto, são as diretrizes para a elaboração de sentenças criminais, oriundas da Lei Anticorrupção Americana (Foreign Corrupt Practices Act [FCPA]), que dispõem sobre os critérios para reconhecer a efetividade dos programas de integridade: comprometimento da alta direção, avaliação de risco, código de conduta, controles internos, treinamento e comunicação, canais de denúncia, investigação interna, diligência prévia (due diligence) e monitoramento (USA, 2012). Posteriormente, os padrões internacionais para a gestão dos sistemas de compliance foram consolidados no padrão gerencial ISO 19600:2014 (International Organization for Standardization [ISSO], 2014).

O Brasil ratificou as três principais convenções internacionais sobre o tema: a Convenção das Nações Unidas contra a Corrupção (United Nations Convention against Corruption [UNCAC], 2003), a Convenção sobre o Combate da Corrupção de Funcionários Públicos Estrangeiros em Transações Comerciais Internacionais da Organização para Cooperação Econômica e o Desenvolvimento (OCDE, 1997) e a Convenção Interamericana contra a Corrupção (CICC), da Organização dos Estados Americanos (OEA, 1996). Entretanto, foi em 2013, com a aprovação da Lei Anticorrupção e a edição do respectivo Decreto regulamentador (Decreto no 8.420/2015), que a implementação de medidas preventivas, como os programas de integridade, foi realmente incentivada, tanto por servir como mitigadora das sanções aplicáveis às empresas que infringem a Lei Anticorrupção quanto pelas exigências comerciais de mercados em que a diligência prévia se tornou prática comum (Cunha \& El Kalay, 2019; Schmidt, 2015). Dentro dessa mesma lógica preventiva, os padrões de governança corporativa também passaram a ser aprimorados nas agências públicas. Primeiro, com a aprovação da Lei das Estatais (Lei no 13.303/2016), que passou a exigir a adoção de boas práticas de governança corporativa, como o compliance nas empresas públicas. Em seguida, com a edição do Decreto da Governança (Decreto no 9.203/2017), que regulamentou a adoção dessas práticas no âmbito dos órgãos da administração pública federal.

A partir de então, determinar as condições por meio das quais os programas de integridade pública podem ser considerados efetivos assumiu uma posição de destaque no recente debate sobre o aprimoramento da governança corporativa das agências públicas brasileiras. Programas efetivos de integridade pública asseguram a conformidade dos agentes e das organizações públicas aos princípios éticos, aos procedimentos administrativos e às normas legais. Ou seja, adotam práticas que visam prevenir e combater atos criminosos e antieconômicos, bem como incentivar a adoção de uma conduta ética orientada à geração de valor público (MOORE, 1995). No entanto, a configuração desses programas de integridade pública varia, justificando uma análise comparativa, de natureza descritiva e classificatória, que permita compreender e aperfeiçoar essas iniciativas. 
Afinal, quais são as principais características dos programas de integridade pública no Brasil? Com o propósito de responder a esse problema de pesquisa, foi realizada uma contextualização do tema à luz dos princípios da governança corporativa das agências públicas. Em seguida, com base nos parâmetros estabelecidos por esse regime anticorrupção, foram criados indicadores que permitem descrever comparativamente esses programas. Os resultados alcançados permitem identificar seus três principais desafios.

\section{OS PROGRAMAS DE INTEGRIDADE NO CONTEXTO DA NOVA GOVERNANÇA PÚBLICA}

A Nova Governança Pública é um modelo que busca aprimorar a legitimidade e o desempenho do governo ao incorporar novos atores ao processo de formulação e implementação das políticas públicas (Osborne, 2006). Seus principais focos de análise são a coordenação governamental do Estado, bem como as relações entre governo e setores privado e social (Peci, Pieranti \& Rodrigues, 2008; Pollit \& Bouckaert, 2011). Para Prats I Catalá (2006), a governança se refere ao reconhecimento da importância da interação entre governo, sociedade civil e setor privado. O modelo estabelece uma orientação para o cidadão, observando geralmente cinco princípios: responsividade, excelência, transparência, participação e conformidade (Kaufmann, Kraay \& Zoido-Lobatón, 2000; Van Doeveren, 2011).

A governança pública enfatiza o processo de geração de valor público pela colaboração entre agentes públicos e privados na produção de serviços, políticas e bens públicos que visam ao desempenho e à conformidade (Martins \& Marini, 2015). Esse modelo ratifica o papel da sociedade civil e das redes de atores públicos, privados e sociais para o controle e o alcance de melhores processos de geração de valor público, associando elevado desempenho com o respeito a princípios de conformidade (Alcantara, 1998).

Mark Bevir (2012) assevera que esse modelo pressupõe que as redes de parceria entre os três setores estatais, ao permitir agregar os recursos dos diversos parceiros e levar suas necessidades em consideração, oferece um modo de coordenação de resultado superior às burocracias (modelo hierárquico) e às empresas (modelo competitivo). Essa parceria, fundada na confiança mútua entre os atores, é firmada por agentes públicos, sociais e privados, assim como por diferentes agentes governamentais (níveis de governo), exigindo uma liderança pública capaz de atuar na criação e na gestão de redes que atuem de forma flexível, criativa, inclusiva e comprometida com o interesse público. Como a nova governança pública está fundada na colaboração e na confiança, as práticas de governança corporativa, como gestão de riscos e integridade, são cada vez mais relevantes para o setor público.

As organizações públicas são cobradas por formas mais eficientes, transparentes, participativas, responsivas e íntegras de gestão, sob pena de não dispor de confiança para coordenar as redes de colaboração necessárias à resolução dos problemas públicos. Além disso, a ampliação do papel regulatório do governo torna mais necessário investir em melhor capacidade para regular a sociedade civil em favor de maior geração de valor público, prevenindo oportunismos, incentivando a cooperação e gerindo adequadamente os incentivos sociais (Lodge \& Wegrich, 2014). Por isso, o modelo da nova governança pública contribui para restabelecer a conformidade (ética e legal), aliada ao desempenho (enfatizado no modelo gerencialista), como condição fundamental à geração de valor público, incorporando as ferramentas de governança corporativa às organizações do setor público (Barreto \& Vieira, 2019).

Shleifer e Vishny (1997) pontuam que a governança está centrada nos processos de direção e controle das organizações, abordando a distribuição de direitos e responsabilidades entre seus integrantes, as regras e os procedimentos para tomada de decisão, assim como a definição dos meios para alcançar os objetivos e os instrumentos para controlar o desempenho. Para Fukuyama (2013), a boa governança agrega uma dimensão normativa, baseada em princípios, ao debate sobre a qualidade da governança pública e corporativa, enfatizando a necessidade de estabelecer cadeias claras de responsabilidade (accountability), observar o pluralismo político e o respeito aos direitos humanos, promover a transparência e a participação e garantir o Estado de direito. Como os objetivos das agências públicas consistem em satisfazer às necessidades dos cidadãos, observando esses princípios, as práticas de governança corporativa se aplicam também ao setor público (Howard \& Seth-Purdie, 2005; Matei \& Drumasu, 2015).

Nesse contexto, os programas de integridade moldam uma estrutura de incentivos que orienta o comportamento dos agentes de forma a alinhá-lo ao interesse público (CGU, 2017; United Nations Office on Drugs and Crime [UNODC], 2012; 
Zenkner, 2019). Esses incentivos visam assegurar a conformidade dos agentes com os princípios éticos, as melhores práticas gerenciais e a observância de leis e normas aplicáveis (compliance). A terminologia empregada pela legislação brasileira (a Lei Anticorrupção, o Decreto da Governança e a Lei das Estatais) denomina os sistemas de compliance, de forma genérica, como programas de integridade, mas ambos se referem à conformidade (ISO, 2014).

Os programas de integridade pública agregam um conjunto de mecanismos e procedimentos com o objetivo de prevenir, detectar e remediar a ocorrência de fraude e corrupção nas organizações, pensadas e implementadas de forma sistêmica, com aprovação da alta direção e sob coordenação de uma área ou pessoa responsável (CGU, 2015b). As agências públicas e corporativas implementam programas de integridade para garantir a conformidade, promover melhores resultados e assegurar sua sustentabilidade, contribuindo para mitigar os riscos de ocorrência dos mais diversos tipos de oportunismo, como fraude, corrupção, conflito de interesse etc.

As diretrizes para elaboração de sentenças criminais (United States Sentencing Commission Guidelines Manual), oriundas da jurisprudência referente à aplicação do FCPA, conhecida como Lei Anticorrupção Americana, estabelece que são considerados efetivos aqueles programas de integridade que observam integralmente as seguintes diretrizes: comprometimento da alta direção, gestão de riscos, código de conduta, controles internos, treinamento e comunicação, canais de denúncia, investigação interna, diligencia prévia (due diligence) e monitoramento (USA, 2018). Em consonância com o referencial internacional, essas diretrizes estão formalmente dispostas nos Decretos 9.203/2017 e 8.420/2015, que detalham as condições para a avaliação de programas efetivos de integridade pública e privada no Brasil.

\section{Quadro 1}

\section{Diretrizes de integridade}

\begin{tabular}{|c|c|}
\hline Diretrizes & Descrição \\
\hline $\begin{array}{l}\text { Suporte da alta } \\
\text { administração }\end{array}$ & $\begin{array}{l}\text { A liderança organizacional deve dar aval explícito e apoio incondicional, além de exercitar } \\
\text { cotidianamente os princípios do programa de integridade, não só como exemplo a ser seguido, } \\
\text { mas também para dar o primeiro passo, de fato, na transformação da cultura da organização, } \\
\text { favorecendo um ambiente ético e íntegro. }\end{array}$ \\
\hline $\begin{array}{l}\text { Gestão de riscos } \\
\text { de integridade }\end{array}$ & $\begin{array}{l}\text { As organizações devem diagnosticar seus riscos e definir os controles necessários para fortalecer } \\
\text { a integridade. }\end{array}$ \\
\hline $\begin{array}{l}\text { Código de } \\
\text { conduta }\end{array}$ & $\begin{array}{l}\text { O código de conduta estabelece as medidas de prevenção a serem observadas e será considerado } \\
\text { na avaliação da efetividade do programa por organismos de controle ou por auditores, } \\
\text { estabelecendo, entre outros tópicos, direitos e obrigações de diretores da organização, gerentes, } \\
\text { empregados, agentes terceirizados e parceiros comerciais. }\end{array}$ \\
\hline $\begin{array}{l}\text { Controles } \\
\text { internos }\end{array}$ & $\begin{array}{l}\text { Os controles internos devem minimizar os riscos operacionais e de integridade de acordo com } \\
\text { os objetivos, as atividades e a apetite de riscos da organização. }\end{array}$ \\
\hline $\begin{array}{l}\text { Comunicação } \\
\text { e treinamento }\end{array}$ & $\begin{array}{l}\text { As partes interessadas (dirigentes, funcionários, clientes, fornecedores etc.) devem ser } \\
\text { comunicadas e treinadas sobre políticas, diretrizes, controles e atividades da organização, de } \\
\text { forma a cumprir seu papel no programa. }\end{array}$ \\
\hline $\begin{array}{l}\text { Canais de denúncia } \\
\text { (ouvidorias) }\end{array}$ & $\begin{array}{l}\text { Canais de denúncia anônimos e confidenciais devem ser criados para permitir que as partes } \\
\text { interessadas reportem ou busquem orientações sobre condutas que violem as orientações do } \\
\text { programa. }\end{array}$ \\
\hline $\begin{array}{l}\text { Investigações } \\
\text { internas }\end{array}$ & $\begin{array}{l}\text { Investigações internas independentes devem ser realizadas para detectar violações, investigar } \\
\text { e remediar irregularidades e sancionar os envolvidos. }\end{array}$ \\
\hline Due diligence & $\begin{array}{l}\text { Verificações prévias (due diligence) devem ser realizadas junto aos colaboradores (internos e } \\
\text { externos) para prevenir danos operacionais e reputacionais à organização. }\end{array}$ \\
\hline Monitoramento & $\begin{array}{l}\text { As atividades devem ser permanentemente monitoradas e aprimoradas, por meio de um } \\
\text { sistema que permita o aprendizado e a adaptação de instrumentos, processos e estruturas em } \\
\text { face dos objetivos da organização. }\end{array}$ \\
\hline
\end{tabular}

Fonte: Elaborado pelos autores, baseado em CGU (2015a), Decreto $n^{\circ} .8 .420$ (2015), USA (2018) e ISO (2014). 


\section{METODOLOGIA}

Esta pesquisa adota um desenho qualitativo de estudo de caso múltiplo, de natureza descritiva e classificatória (Blaikie, 2010; Chmiliar, 2010; Gerring, 2001). Tal abordagem, que se vale da dedicação típica dos estudos em profundidade, replica a análise de uma série instrumental de estudos de caso, permitindo a generalização dos resultados e se aproximando da lógica dos desenhos transversais (Galloway \& Sheridan, 1994; Yin, 2010).

No Brasil, em fevereiro de 2019, havia doze programas de integridade pública nos órgãos da administração pública direta. Desses, sete são vinculados à administração federal; dois, à estadual; e três, à municipal. Esses casos foram analisados com base em 36 indicadores, organizados segundo as nove diretrizes dispostas no regime nacional e internacional anticorrupção. Cada indicador foi desenvolvido baseado num conjunto de referências legais e acadêmicas sobre as práticas efetivas de compliance (conforme Quadro 3, no Apêndice).

Os dados foram coletados em 79 documentos (unidades hermenêuticas), como manuais, guias, planos, códigos de ética e conduta, relatórios de investigações e auditorias, portarias, resoluções, editais, contratos e endereço eletrônico, disponibilizados pelas respectivas organizações. A utilização desses documentos oficiais, de natureza pública, contribui para reforçar os critérios de autenticidade, credibilidade, representatividade e significado que asseguram a qualidade da fonte de informação e permitem a replicação da análise (Bryman, 2008; Scott, 1990).

Quadro 2

\section{Casos e unidades hermenêuticas}

\begin{tabular}{|c|l|c|}
\hline \multirow{4}{*}{ Esfera } & \multicolumn{1}{|c|}{ Programas de integridade pública } & \multicolumn{1}{c|}{$\begin{array}{c}\text { Unidades } \\
\text { hermenêuticas }\end{array}$} \\
\hline \multirow{5}{*}{ Federal } & Casa Civil da Presidência da República & 4 \\
\cline { 2 - 3 } & Controladoria-Geral da União & 8 \\
\cline { 2 - 3 } & Ministério de Agricultura, Pecuária e Abastecimento & 5 \\
\cline { 2 - 3 } & Ministério da Defesa & 8 \\
\cline { 2 - 3 } & Ministério da Fazenda (Economia) & 5 \\
\cline { 2 - 3 } & Ministério das Cidades (Desenvolvimento Regional) & 3 \\
\cline { 2 - 3 } & Ministério de Desenvolvimento, Planejamento e Gestão & 9 \\
\hline \multirow{3}{*}{ Estadual } & Controladoria-Geral do Estado de Minas Gerais & 12 \\
\cline { 2 - 3 } & Secretaria da Fazenda do Estado de Alagoas & 8 \\
\hline \multirow{5}{*}{ Municipal } & Município de Aracati/CE & 4 \\
\cline { 2 - 3 } & Município de Belo Horizonte/MG & 5 \\
\cline { 2 - 3 } & Secretaria do Verde e do Meio Ambiente - São Paulo/SP & \\
\hline
\end{tabular}

Fonte: Elaborado pelos autores.

A classificação dos casos observou uma escala de aderência ao quesito, com variação de 0 a 2 , na qual 0 significa "não atende", 1 significa "atende parcialmente" e 2 significa "atende". É utilizada uma medida parcial de atendimento ao quesito porque é possível observar situações em que a prática está prevista nos regulamentos, mas não existe evidência de implementação, ou há evidência de que seja parcialmente implementada. As fontes dos dados e os critérios específicos de classificação de cada indicador são apresentados no Quadro 3, no Apêndice. 


\section{ANÁLISE DOS PROGRAMAS DE INTEGRIDADE PÚBLICA}

Os resultados indicam que o programa de integridade pública com maior aderência às práticas nacionais e internacionais é o da Controladoria-Geral do Estado de Minas Gerais, que atende a $91 \%$ dos quesitos, e o de menor aderência é o do município de Aracati, no Ceará, que atende a $41 \%$ dos quesitos.

Tabela 1

Resultados por programa

\begin{tabular}{|c|c|c|}
\hline Esfera & Programas de integridade pública & Percentual \\
\hline \multirow{7}{*}{ Federal } & Casa Civil da Presidência da República & $80,56 \%$ \\
\hline & Controladoria-Geral da União & $83,33 \%$ \\
\hline & Ministério de Agricultura, Pecuária e Abastecimento & $77,78 \%$ \\
\hline & Ministério da Defesa & $69,44 \%$ \\
\hline & Ministério da Fazenda (Economia) & $80,56 \%$ \\
\hline & Ministério das Cidades (Desenvolvimento Regional) & $58,33 \%$ \\
\hline & Ministério de Desenvolvimento, Planejamento e Gestão & $66,67 \%$ \\
\hline \multirow{2}{*}{ Estadual } & Controladoria-Geral do Estado de Minas Gerais & $91,67 \%$ \\
\hline & Secretaria da Fazenda do Estado de Alagoas & $66,67 \%$ \\
\hline \multirow{4}{*}{ Municipal } & Município de Aracati/CE & $41,67 \%$ \\
\hline & Município de Belo Horizonte/MG & $58,33 \%$ \\
\hline & Secretaria do Verde e do Meio Ambiente - São Paulo/SP & $58,33 \%$ \\
\hline & & $69,44 \%$ \\
\hline
\end{tabular}

Fonte: Elaborada pelos autores.

Em média, aproximadamente $70 \%$ das práticas de integridade do regime nacional e internacional foram atendidas, ou parcialmente atendidas, pelos programas de integridade pública analisados. Além disso, cerca de $90 \%$ dos programas de integridade pública dispõem de canais de denúncia, embora somente $40 \%$ adotem práticas de diligências prévias (due diligence).

Tabela 2

Resultados por indicador

\begin{tabular}{l|c|c}
\hline \multicolumn{1}{c|}{ Indicadores } & Atende & $\begin{array}{c}\text { Atende } \\
\text { parcialmente }\end{array}$ \\
\hline 1. Suporte da alta administração & $\mathbf{6 6 , 6 7 \%}$ & $\mathbf{6 , 2 5 \%}$ \\
\hline 1.1. Critérios de escolha da alta gestão & $33,33 \%$ & $25,00 \%$ \\
\hline 1.2. Aprovação de políticas pela alta gestão & $100,00 \%$ & $0,00 \%$ \\
\hline 1.3. Manifestações de apoio assinadas pela alta gestão & $75,00 \%$ & $0,00 \%$ \\
\hline 1.4, Participação da alta gestão em treinamentos de integridade & $58,33 \%$ & $0,00 \%$ \\
\hline 2. Gestão de riscos de integridade & $\mathbf{7 0 , 8 3 \%}$ & $\mathbf{2 , 0 8 \%}$ \\
\hline 2.1. Realização de gestão de riscos de integridade & $83,33 \%$ & $0,00 \%$ \\
\hline 2.2. Utilização da gestão de riscos em processos decisórios & $75,00 \%$ & $8,33 \%$ \\
\hline 2.3. Controle de má administração de recursos & $66,67 \%$ & $0,00 \%$ \\
\hline 2.4. Relatórios de execução de protocolos de riscos & $58,33 \%$ & $0,00 \%$ \\
\hline 3. Código de conduta e práticas de compliance & $\mathbf{7 2 , 9 2 \%}$ & $\mathbf{2 , 0 8 \%}$ \\
\hline 3.1. Comissão de Ética formalmente instituída & $100,00 \%$ & $0,00 \%$ \\
\hline 3.2. Código de Ética e Conduta próprio & $\mathbf{7 5 , 0 0 \%}$ & $\mathbf{8 , 3 3 \%}$ \\
\hline 3.3. Previsão de aplicação de sanções & $58,33 \%$ & $0,00 \%$ \\
\hline 3.4. Ações de divulgação do Código de Conduta e Ética & $58,33 \%$ & $0,00 \%$ \\
\hline
\end{tabular}




\begin{tabular}{|c|c|c|}
\hline Indicadores & Atende & $\begin{array}{c}\text { Atende } \\
\text { parcialmente }\end{array}$ \\
\hline 4. Controles internos & $70,83 \%$ & $2,08 \%$ \\
\hline 4.1. Auditoria interna estruturada & $91,67 \%$ & $0,00 \%$ \\
\hline 4.2. Cumprimento do objeto contratual & $100,00 \%$ & $0,00 \%$ \\
\hline 4.3. Segregação de funções & $41,66 \%$ & $8,33 \%$ \\
\hline 4.4. Revisão de controles internos & $50,00 \%$ & $0,00 \%$ \\
\hline 5. Treinamento e comunicação & $75,00 \%$ & $2,08 \%$ \\
\hline 5.1. Capacitações relacionadas à ética e à integridade & $91,67 \%$ & $0,00 \%$ \\
\hline 5.2. Participação da instância de integridade em treinamentos & $83,33 \%$ & $0,00 \%$ \\
\hline 5.3. Capacitação a novos servidores & $41,67 \%$ & $0,00 \%$ \\
\hline 5.4. Divulgação de valores e padrões de conduta & $83,33 \%$ & $8,33 \%$ \\
\hline 6. Canais de denúncia (ouvidorias) & $83,33 \%$ & $8,33 \%$ \\
\hline 6.1. Disponibilização de canais de denúncia & $91,67 \%$ & $8,33 \%$ \\
\hline 6.2. Tratamento adequado a qualquer manifestação & $100,00 \%$ & $0,00 \%$ \\
\hline 6.3. Indicação expressa de garantias de proteção à identidade & $58,33 \%$ & $25,00 \%$ \\
\hline 6.4. Divulgação dos canais de denúncia & $83,33 \%$ & $0,00 \%$ \\
\hline 7. Investigações internas & $37,50 \%$ & $4,17 \%$ \\
\hline 7.1. Corregedoria instituída & $83,33 \%$ & $8,33 \%$ \\
\hline 7.2. Agentes corregedores devidamente capacitados & $41,67 \%$ & $8,33 \%$ \\
\hline 7.3. Participação em eventos de integridade & $16,67 \%$ & $0,00 \%$ \\
\hline 7.4. Relatórios de execução de investigações internas & $8,33 \%$ & $0,00 \%$ \\
\hline 8. Due diligence & $33,33 \%$ & $6,25 \%$ \\
\hline 8.1. Cláusula contratual anticorrupção & $25,00 \%$ & $0,00 \%$ \\
\hline 8.2. Terceiros declaram ciência de normas e padrões éticos & $33,33 \%$ & $0,00 \%$ \\
\hline 8.3. Verificação de programas de integridade em terceiros & $25,00 \%$ & $25,00 \%$ \\
\hline 8.4. Regras e procedimentos nas interações público-privadas & $50,00 \%$ & $0,00 \%$ \\
\hline 9. Monitoramento e auditoria & $77,08 \%$ & $4,17 \%$ \\
\hline 9.1. Instância de integridade formalmente instituída & $83,33 \%$ & $8,33 \%$ \\
\hline 9.2. Servidores dedicados exclusivamente & $75,00 \%$ & $8,33 \%$ \\
\hline 9.3. Acesso ao nível hierárquico mais elevado & $75,00 \%$ & $0,00 \%$ \\
\hline 9.4. Relatórios de ações de monitoramento & $75,00 \%$ & $0,00 \%$ \\
\hline Média & $65,28 \%$ & $4,17 \%$ \\
\hline
\end{tabular}

Fonte: Elaborada pelos autores. 
A classificação dos programas de integridade pública, segundo as nove diretrizes do referencial anticorrupção, descreve a situação geral dos casos em relação aos indicadores. A Figura 1 permite visualizar os principais resultados que descrevem menor ocorrência dos indicadores relacionados a investigações internas (7) e verificação prévia - due diligence (8).

Figura 1

\section{Classificação dos programas públicos de integridade}

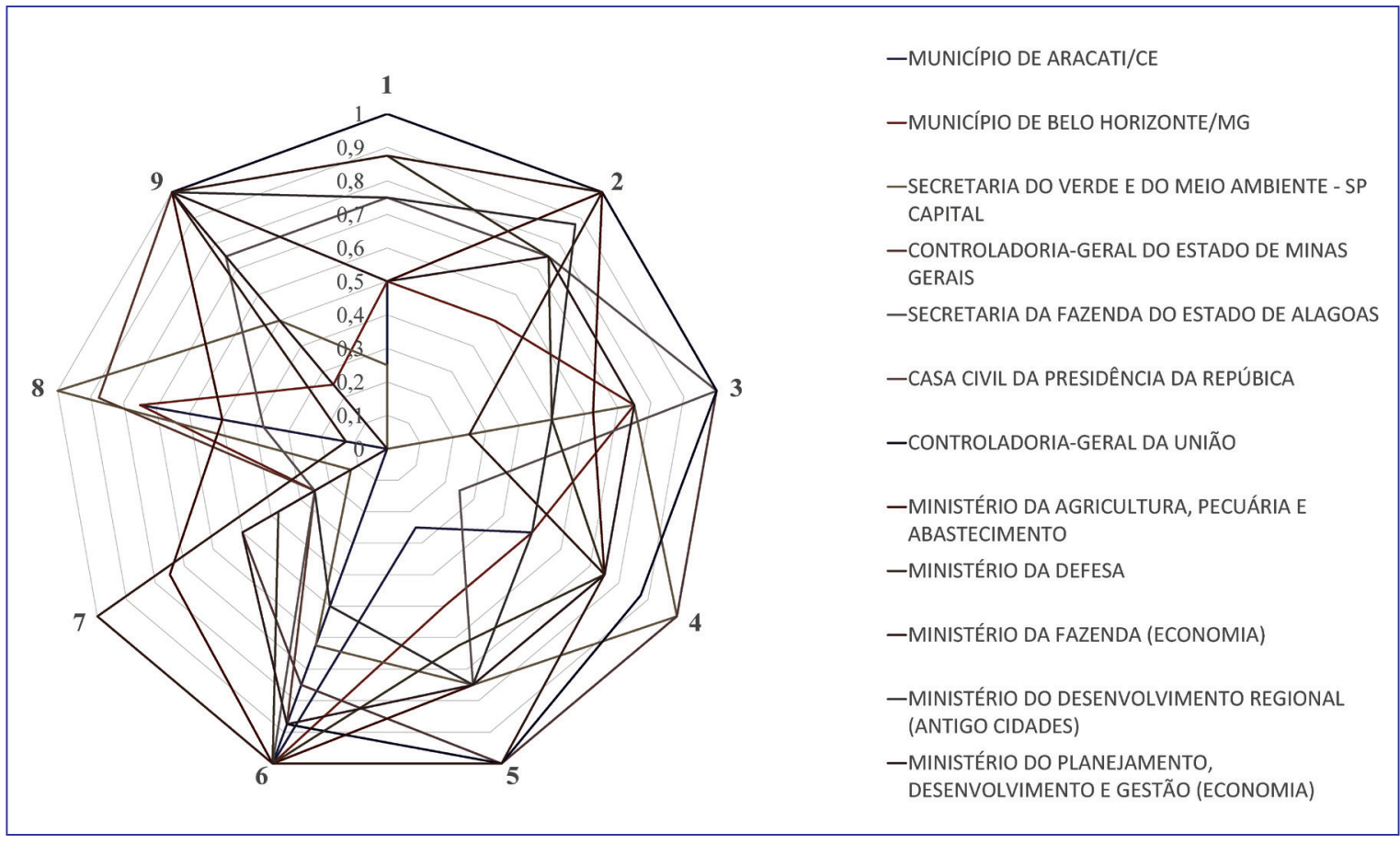

Fonte: Elaborada pelos autores.

Os resultados da pesquisa indicam três desafios ao processo de efetivação dos programas de integridade na administração pública brasileira: adoção das práticas de verificação prévia (due diligence), desalinhamento entre os canais de denúncia e as investigações internas, singularidades da gestão de integridade nos municípios.

O primeiro desafio está vinculado a uma diretriz fundamental a quaisquer programas de integridade: a verificação prévia. Essa diretriz exige que a organização adote procedimentos com a devida diligência, no sentido de zelo ou dedicação ao alcance efetivo da integridade. Na prática, quanto mais complexa a natureza da atividade desenvolvida pela organização pública, maior deverá ser sua rede de fornecedores, prestadores de serviços e agentes intermediários contratados para representá-la em diferentes situações. Consequentemente, aumenta o risco de que algum desses agentes contratados se envolva em situações ilegais ou antiéticas, com potencial para gerar danos econômicos, à imagem, ou implicar sua responsabilização legal (CGU, 2015a, p. 61).

Para mitigar esses riscos de integridade, as organizações públicas devem adotar práticas de verificação prévia à contratação, além de medidas visando à supervisão de terceiros contratados, sobretudo em situações de elevado perfil de risco à integridade, como a licitação de obras públicas. Essas medidas verificam aspectos financeiros, reputacionais, regulatórios e jurídicos, possibilitando a reunião de informações sobre a empresa que pretende ser contratada, bem como sobre seus representantes, incluindo sócios e administradores, de modo a certificar que não há situações impeditivas à contratação, a fim de determinar o grau de risco do contrato e realizar uma supervisão adequada (Giovanini, 2014; Serpa, 2016).

A análise das informações decorrentes do processo de due diligence devem ser estruturadas de forma a apoiar os gestores no processo de tomada de decisão acerca da contratação e da eventual gestão dos contratos celebrados. Desse modo, o due diligence pode ser um valioso instrumento de proteção dos gestores públicos, trazendo maior segurança para sua atuação, em face da responsabilização possível em razão de circunstâncias como a omissão imprópria ou a cegueira deliberada 
(Pironti, 2018). O gestor público que verificar, durante o processo de due diligence, pontos de atenção deve acompanhar com mais afinco a execução contratual com o objetivo de prevenir superfaturamentos, inexecuções totais ou parciais do objeto, fraudes nas medições dos contratos, entre outras ilegalidades e irregularidades.

Os resultados da análise de dados empíricos, entretanto, revelam um baixo índice de implementação de práticas de due diligence na administração pública - 39\% dos casos. É possível observar, por exemplo, que nenhum dos programas federais analisados inclui cláusula anticorrupção em suas minutas contratuais ou solicita que os terceiros contratados declarem ciência da existência do Código de Ética ou Conduta da organização. Além disso, contribui para esse resultado a ausência de uma regulamentação específica que discipline a forma como os programas de integridade pública podem estipular parâmetros para a contratação. Sem dúvidas, entre todas as diretrizes, a due diligence é a que dispõe de maior potencial de impacto para a qualificação do ambiente de negócios públicos e a disseminação de uma cultura de integridade na sociedade brasileira, pois sua exigência nas contratações pode criar um efeito positivo em cascata em toda a cadeia econômica. Dessa forma, mesmo que os programas de integridade empresarial sejam facultativos, economicamente passaria a ser inviável atuar no mercado sem compromisso efetivo com a integridade pública.

O segundo desafio decorre do desalinhamento entre canais de denúncia e investigações internas. O controle é uma atividade intrínseca a qualquer organização, pública ou privada. Controles internos estruturados contribuem diretamente para a redução do número de fraudes ou desvios éticos numa organização (Cavalcante, 2017; Giovanini, 2014, 2016). Assim, embora os resultados da pesquisa revelem uma elevada ocorrência dessa prática $-72 \%$ dos casos -, tal iniciativa isolada não é suficiente. Para além dos controles internos, os programas efetivos de integridade recorrem aos canais de denúncia - ouvidorias, amplamente difundidas no setor público - para iniciar investigações internas ou externas independentes - presentes em apenas $41 \%$ dos casos - que permitam identificação, processamento e eventual sanção dos casos suspeitos de irregularidades.

Veríssimo (2017) e Gonsales e Eslar (2016) apontam que constituir e publicar um sistema - que deve incluir mecanismos que permitam anonimato e confidencialidade - por meio do qual empregados e agentes da organização possam reportar ou buscar orientação sobre potenciais ou reais condutas antiéticas ou ilícitas sem medo de sofrer retaliação é um dos pressupostos de efetividade dos programas de integridade, visto que representam uma oportunidade de detecção e resolução antecipada de problemas.

Os canais de denúncia são uma das principais fontes de identificação de fraudes ou desvios na administração pública, porém devem ser aliados a protocolos de investigação interna que permitam processar apropriadamente as denúncias de violação (Giovanini, 2014). Tais processos devem garantir que os fatos sejam verificados, que as responsabilidades sejam identificadas, além de, caso necessário, definir sanções e ações corretivas mais adequadas àqueles que não compartilham dos mesmos compromissos éticos, gerenciais e legais. A pronta resposta demonstra o compromisso da organização em agir de forma correta.

O uso de ferramentas de investigação adequadas ao tratamento de situações de não conformidade, instrumentalizadas por meio de uma corregedoria atuante e capacitada em temas de integridade, deve garantir a uniformidade de ação em todos os casos denunciados e assegurar a execução de todos os passos necessários à identificação e à responsabilização. Aliás, busca-se com isso corrigir o problema e evitar sua repetição futura, cumprindo importante função no planejamento do programa de integridade. Por outro lado, em não se levando adiante a persecução das denúncias recebidas e a consequente punição aos envolvidos, compromete-se não só o sucesso, mas principalmente a credibilidade dos programas de integridade.

O terceiro desafio diz respeito às particularidades da gestão de integridade pública nos municípios. Em média, os programas municipais analisados atendem apenas a $52 \%$ das práticas. Isso ocorre, em geral, pela ausência de práticas de gestão de riscos de integridade (16,67\%), investigações internas $(16,67 \%)$ e monitoramento (33,33\%). À exceção da diretriz "investigações internas", que contou com pouca adesão em toda a amostra, os dados referentes à gestão de riscos de integridade e monitoramento apresentam resultados incomuns para os demais casos analisados.

A ausência de práticas de gestão de riscos nos programas de integridade da esfera municipal deixa transparecer de imediato uma possível fragilidade na capacidade gerencial que, por si só, compromete a efetividade das medidas anticorrupção. A ausência da avaliação periódica de "riscos de conformidade" - que compromete a adoção de medidas apropriadas para aperfeiçoar o desenho e a implementação de sua gestão de integridade - e a baixa competência de "monitoramento" na esfera municipal são indicadores dessa possível falta de capacidade gerencial. 
Aliado a isso, o reduzido "suporte da alta administração" entre os programas municipais parece corroborar a ideia de que o desafio gerencial a ser superado na gestão de integridade da administração direta municipal é maior em razão de uma possível menor capacidade gerencial. Segundo Melo (2019), a ausência de uma determinação clara e transparente da gestão da integridade na estrutura do órgão público compromete os diversos instrumentos e atores que a compõem.

\section{CONSIDERAÇÕES FINAIS}

Esta pesquisa contribui para descrever e comparar as práticas adotadas pelos programas de integridade pública brasileira com os critérios definidos pelo regime nacional e internacional anticorrupção, permitindo identificar os principais desafios para seu aprimoramento. Dessa forma, o estudo ajuda a ampliar o conhecimento sobre a integridade pública ao incorporar evidências sobre as práticas que estão sendo de fato adotadas pelas agências públicas brasileiras.

Os resultados da pesquisa evidenciam que, apesar de existir um número reduzido de programas de integridade pública - somente doze em janeiro de 2019-, há um considerável alinhamento das práticas de promoção de integridade desses programas com os referenciais nacionais e internacionais. Antes da nova regulamentação que instituiu os programas de integridade, como a edição do Decreto da Governança Pública, comissões de ética e ouvidorias já existiam, facilitando a assimilação aos novos programas que, de forma concatenada, visam dar maior efetividade à promoção da integridade pública. Entretanto, mesmo no governo federal, como em normas regulamentadoras (Portarias CGU no 1.089/2018 e 57/2019), a adesão dos órgãos da administração pública, num primeiro momento, foi reduzida. Por isso, outras limitações, para além daquelas apontadas neste estudo, como a baixa adesão das agências públicas às novas práticas de governança corporativa, ainda precisam ser devidamente explicadas.

A gestão da integridade traz consigo uma série de inovações a serem absorvidas pelas agências públicas, na forma como devem gerir os recursos humanos, realizar as compras, gerenciar os riscos e os controles internos etc. Em razão dessa transversalidade, o tema tem grande potencial para pesquisas futuras que visem explicar as configurações desses programas possivelmente replicando os indicadores desta pesquisa -, analisar em detalhe a adoção dessas práticas para cada uma dessas dimensões administrativas ou avaliar seus resultados sobre a qualidade do serviço público. No Brasil, a gestão dos programas de integridade pública está só começando, e os resultados possíveis para o aprimoramento da gestão podem ser muito promissores. 


\section{REFERÊNCIAS}

Alcantara, C. H. (1998). Uses and Abuses of the Concept of Governance. International Social Science Journal, 50(155), 105-113.

Alliance for Integrity. (2015). Compliance Handbook. Recuperado de https://www.allianceforintegrity.org/

Austin Rating. (2013). Manual de controles internos e compliance. Recuperado de http://www.austin.com.br/Assuntos-Regulatorios/ Documentos/Manual-de-Compliance.html

Barreto, R. T. S., \& Vieira, J. B. (2019). Governança, gestão de riscos e integridade. Brasília, DF: Enap.

Bevir, M. (2012). Governance: a very short introduction. Oxford, UK: Oxford University Press.

Blaikie, N. (2010). Designing Social Science. Malden, MA: Polity Press. Bryman, A. (2008). Social Research Methods (4a ed.). Oxford, UK: OUP. Cavalcante, R. J. (2016). O controle externo da Lei Anticorrupção. In J. Munhós, R. P. Queiroz (Orgs.), Lei anticorrupção e temas de compliance (2a ed., pp. 407-442). Salvador, BA: Editora JusPodivm.

Chmiliar, L. (2010). Multiple-Case Designs. In A. Mills, G. Eurepos, \& E. Wiebe (Eds.), Encyclopedia of Case Study Research. London, UK: Sage.

Coelho, C. C. B. P. (2016). Compliance na administração pública: uma necessidade para o Brasil. Revista de Direito da Faculdade Guanambi, 3(1), 75-95.

Committee of Sponsoring Organizations of the Treadway Commission. (2013). COSO Enterprise Risk Management-Integrated Framework. Jersey City, NJ: Autor.

Controladoria-Geral da União. (2015a). Ministério da Transparência e Controladoria-Geral da União. Guia de Integridade Pública. Brasília, DF.

Controladoria-Geral da União. (2015b). Ministério da Transparência e Controladoria-Geral da União. Guia de Implementação de Programas de Integridade nas Empresas Estatais. Brasília, DF.

Controladoria-Geral da União. (2017). Ministério da Transparência e Controladoria-Geral da União. Manual para implementação de programas de integridade. Brasília, DF.

Controladoria-Geral da União. (2018a). Ministério da Transparência e Controladoria-Geral da União. Manual Prático de Avaliação de Programa de Integridade em PAR. Brasília, DF.

Controladoria-Geral da União. (2018b). Ministério da Transparência e Controladoria-Geral da União. Metodologia de Gestão de Riscos. Brasília, DF.

Controladoria-Geral da União. (2018c). Ministério da Transparência e Controladoria-Geral da União. Plano de Integridade da CGU. Brasília, DF.

Cunha, M., \& El Kalay, M. (2019). Manual de Compliance: Compliance Mastermind. São Paulo, SP: LAC Editora.

Decreto $n^{\circ}$. 8.420, de 18 de março de 2015. (2015). Regulamenta a Lei no 12.846 , de 1 de agosto de 2013, que dispõe sobre a responsabilização administrativa de pessoas jurídicas pela prática de atos contra a administração pública, nacional ou estrangeira e dá outras providências. Diário Oficial [da] República Federativa do Brasil, Brasília, DF.
Recuperado de http://www.planalto.gov.br/ccivil_03/_Ato20152018/2015/Decreto/D8420.htm

Decreto no 9.203, de 22 de novembro de 2017. (2017). Dispõe sobre a política de governança da administração pública federal direta, autárquica e fundacional. Diário Oficial [da] República Federativa do Brasil, Brasília, DF. Recuperado de http://www.planalto.gov.br/ ccivil_03/_ato2015-2018/2017/decreto/D9203.htm

Empirica Investimentos. (2016). Manual de Controles Internos e Compliance. São Paulo, SP: Empírica.

Fukuyama, F. (2013). What is Governance? (CGD Working Paper, 314). Washington, DC: Center for Global Development.

Galloway, J., \& Sheridan, S. (1994). Implementing scientific practices through case studies: Examples using home-school interventions and consultation. Journal of School Psychology, 32, 385-413.

Gerring, J. (2001). Social Science Methodology: A Criterial Framework. Cambridge, UK: Cambridge University Press.

Giovanini, W. (2014). Compliance: a excelência na prática. São Paulo, SP: Compliance Total.

Giovanini, W. (2016). Programas de compliance e anticorrupção: importância e elementos essenciais. In J. Munhós, \& R. P. Queiroz (Orgs.), Lei anticorrupção e temas de compliance (pp. 457-474, 2a ed.). Salvador, BA: Editora JusPodivm.

Gonsales, A., \& Eslar, K. D. (2016). Como avaliar a efetividade de um programa de compliance. In J. Munhós, \& R. P. Queiroz (Orgs.), Lei anticorrupção e temas de compliance (pp. 493-508, 2a ed.). Salvador, BA: Editora JusPodivm.

Howard, C., \& Seth-Purdie, R. (2005). Governance Issues for Public Sector Boards. Australian Journal of Public Administration, 64(3), 56-68.

Instituto Brasileiro de Direito e Ética Empresária. (2017). Código de Compliance Corporativo: guia de melhores práticas de compliance no âmbito empresarial. Recuperado de http://ibdee.org.br/wp-content/ uploads/2017/05/IBDEE-2017-Guia-Compliance-digital.pdf

Instituto Brasileiro de Governança Corporativa. (2015). Código das melhores práticas de governança corporativa (5a ed.). São Paulo, SP: Autor.

Instituto Brasileiro de Governança Corporativa. (2018). Métrica de governança corporativa. São Paulo, SP: Autor.

Instituto Ethos. (2017). Indicadores Ethos para negócios sustentáveis e responsáveis. Ciclo 2017/2018. São Paulo, SP: Autor.

Instituto Ethos. (2016). Questionário de avaliação do selo pró-ética. São Paulo, SP: Autor.

International Organization for Standardization. (2014). ISO 19600: 2014 - Compliance management systems - Guidelines. Genève, Suisse: Autor.

International Organization for Standardization. (2019). ISO 31000: 2009-Risk assessment systems - Guidelines. Genève, Suisse: Autor. 
Kaufmann, D., Kraay, A., \& Zoido-Lobatón, P. (2000, June). Governance Matters: From Measurement to Action. Finance and Development, 37(2), 10-13.

LEC Compliance. (2017). Os pilares do programa de compliance. São Paulo, SP: LEC: E-book.

LEC Compliance. (2018). Compliance Risk Assessment em 8 passos. São Paulo, SP: LEC: E-book.

Lei 12.813 de 16 de maio de 2013. (2013). Dispõe sobre o conflito de interesses no exercício de cargo ou emprego do Poder Executivo federal e impedimentos posteriores ao exercício do cargo ou emprego; e revoga dispositivos da Lei no 9.986, de 18 de julho de 2000, e das Medidas Provisórias nos 2.216-37, de 31 de agosto de 2001, e 2.22545, de 4 de setembro de 2001. Diário Oficial [da] República Federativa do Brasil, Brasília, DF. Recuperado de http://www.planalto.gov.br/ ccivil_03/_Ato2011-2014/2013/Lei/L12813.htm

Lei $n$ o 12.846, de 1 o de agosto de 2013. (2013). Dispõe sobre a responsabilização administrativa e civil de pessoas jurídicas pela prática de atos contra a administração pública, nacional ou estrangeira, e dá outras providências. Diário Oficial [da] República Federativa do Brasil, Brasília, DF. Recuperado de http://www.planalto.gov.br/ ccivil_03/_ato2011-2014/2013/lei/l12846.htm

Lei no 13.303, de 30 de junho de 2016. (2016). Dispõe sobre o estatuto jurídico da empresa pública, da sociedade de economia mista e de suas subsidiárias, no âmbito da União, dos Estados, do Distrito Federal e dos Municípios. Diário Oficial [da] República Federativa do Brasil, Brasília, DF. Recuperado de http://www.planalto.gov.br/ ccivil_03/_ato2015-2018/2016/lei/l13303.htm

Lodge, M., \& Wegrich, K. (2014). The Problem-solving Capacity of the Modern State. Oxford, UK: Oxford University Press.

Lynn, L. E., Jr., Heinrich, C. J., \& Hill, C. J. (2000). Studying Governance and Public Management: Challenges and Prospects. Journal of Public Administration Research and Theory, 10(2), 233-261.

Manacorda, S. (2014). Towards an Anti-bribery Compliance Model: Methods and Strategies for a Hybrid Normativity. In S. Manacorda, F. Centonze, \& G. Forti (Eds.), Preventing Corporate Corruption: The Anti-Bribery Compliance Model. Basel, Switzerland: Springer

Martins, H. F., \& Marini, C. (2015). Governança pública contemporânea: uma tentativa de dissecação conceitual. Revista do TCU, 130, 42-53.

Matei, A., \& Drumasu, C. (2015). Corporate Governance and Public Sector Entities. 4 ed. World Conference on Business, Economics and Management (WCBEM). Procedia Economics and Finance, 26, 495-504.

Melo, V. (2019). Programas de conformidade e a busca de integridade em organizações. Brasília, DF: Ipea.

Moore, M. (1995). Creating Public Value: Strategic Management in Government. Cambridge, MA: Harvard University Press.

Organization for Economic Co-operation and Development. (2018). Integridade pública: recomendação do conselho da OCDE sobre integridade pública. Recuperado de www.oecd.org/gov/ethics

Osborne, S. (2010). The New Public Governance? Emerging Perspectives on the Theory and Practice of Public Governance. London, UK: Routledge.
Peci, A., Pieranti, O. P., \& Rodrigues, S. (2008). Governança e New Public Management: convergências e contradições no contexto brasileiro. Organizações \& Sociedade, 15(46), 39-55.

Pironti, R. (2018, setembro 01). Due diligence pode ser instrumento de defesa dos gestores da empresa. Consultor Jurídico. Recuperado de https://www.conjur.com.br/2018-set-01/ rodrigo-pironti-due-diligence-instrumento-defesa-empresa

Pollitt, C., \& Bouckaert, G. (2000). Public Management Reform: A Comparative Analysis. Oxford, UK: Oxford University Press

Prats I Catalá, J. (2006). Veinte años de modernización administrativa en los países de la OCDE. Leciones aprendidas. In Projeto de Modernizacion del Estado. Seminário Internacional sobre Modernizacion del Estado. Buenos Aires, Argentina.

Rhodes, R. (1996). The New Governance: Governing without Government. Political Studies, 44(4), 652-667.

Schmidt, A. Z. (2015). Direito penal econômico: parte geral. Porto Alegre, RS: Livraria do Advogado.

Scott, J. (1990). A matter of record. Cambridge, UK: Polity.

Serpa, A. C. (2016). Compliance descomplicado: um guia simples e direto sobre programas de compliance. São Paulo, SP: Createspace Independent Publishing.

Shleifer, A., \& Vishny, R. (1997). A Survey of Corporate Governance. Journal of Finance, 52(2), 737-783.

Tribunal de Contas da União. (2014). Referencial básico de governança: aplicável a órgãos e entidades da administração pública. Brasília, DF: Autor.

United Nations Office on Drugs and Crime. (2012). Corruption Prevention to Foster Small and Medium Sized Enterprise Development (vol. 2). Vienna, Austria: Autor.

United States of America. (1977). Foreign Corrupt Practices Act. 1977. Recuperado de https://www.justice.gov/criminal-fraud/ foreign-corrupt-practices-act

United States of America. (2012). Foreign Corrupt Practices Act. A resource guide do the U.S. Foreign Corrupt Practices Act. 2012. Recuperado de https://www.justice.gov/criminal-fraud/fcpa-guidance

United States of America. (2018). United States Sentencing Commission Guidelines Manual. Recuperado de http://www.ussc.gov/ guidelines-manual/2015/2015-individual-chapters-and-guidelines-html

United States Sentencing Commission. (2015). United States Sentencing Comission. Effective Compliance and Ethics Program. §8B2.1. Chapter 8. Washington, DC: Autor.

US Department of Justice. (2019, abril). Evaluation of Corporate Compliance Programs (Guidance Document). Recuperado de https:// www.justice.gov/criminal-fraud/page/file/937501

Van Doeveren, V. (2011). Rethinking good governance. Public Integrity, 16(4), 301-318

Vlassis, D. (2014). An anticorruption Ethics and Compliance Program for Business: A practical Guide. In S. Manacorda, F. Centonze, \& G. Forti (Eds.), Preventing Corporate Corruption: The Anti-Bribery Compliance Model. Basel, Switzerland: Springer. 
Veríssimo, C. (2017). Compliance: incentivo à adoção de medidas anticorrupção. São Paulo, SP: Saraiva.

World Bank Group. (2010). Integrity Compliance Guidelines. Washington, DC: Autor.
Yin, R. K. (2010). Estudo de caso: planejamento e métodos (4a ed.). Porto Alegre, RS: Bookman.

Zenkner, M. (2019). Integridade governamental e empresarial: um espectro da repressão e da prevenção à corrupção no Brasil e em Portugal. Belo Horizonte, MG: Fórum.

Rodrigo Tavares de Souza Barreto

ORCID: https://orcid.org/0000-0002-4885-9928

Mestre em Gestão Pública e Cooperação Internacional pela Universidade Federal da Paraíba (UFPB); Gestor de Integridade do Instituto Federal da Paraíba (IFPB). E-mail: rodrigo.tsb@hotmail.com

James Batista Vieira

ORCID: https://orcid.org/0000-0002-3564-3677

Doutor em Ciência Política pelo Instituto de Estudos Sociais e Políticos da Universidade do Estado do Rio de Janeiro (UERJ); Professor adjunto do Departamento de Gestão Pública da Universidade Federal da Paraíba (UFPB). E-mail: james@ccsa.ufpb.br 


\section{APÊNDICE}

\section{Quadro 3 \\ Indicadores}

\begin{tabular}{|c|c|c|c|}
\hline $\begin{array}{l}\text { 1. Suporte da Alta } \\
\text { Administração }\end{array}$ & Referências & Fonte dos Dados & Classificação \\
\hline $\begin{array}{l}\text { 1.1 A organização possui critérios } \\
\text { formalizados para escolha dos } \\
\text { membros da alta gestão que } \\
\text { incluam elementos de integridade, } \\
\text { dentre eles o não envolvimento em } \\
\text { atos de corrupção? }\end{array}$ & $\begin{array}{l}\text { IBGC (2015, 2018); CGU (2015a, } \\
\text { 2015b; 2017, 2018a, 2018c); TCU } \\
\text { (2014); Alliance for Integrity (2015); } \\
\text { WBG (2010); OCDE (2018); Lei № } \\
\text { 12.846/2013; Decreto 5.450/05; } \\
\text { Austin Rating (2013). }\end{array}$ & $\begin{array}{l}\text { Análise documental em manuais, } \\
\text { guias, planos e Programas de } \\
\text { Integridade, códigos de Ética e } \\
\text { Conduta, portarias de nomeação } \\
\text { e resoluções que disciplinem a } \\
\text { matéria. }\end{array}$ & $\begin{array}{l}\text { "0" = não atende (ausência de } \\
\text { disposição regulamentar e evidência } \\
\text { formal de implementação); } \\
\text { "1" = atende parcialmente (prática } \\
\text { prevista programaticamente, mas } \\
\text { até então não implementada OU } \\
\text { implementada parcialmente; } \\
\text { "2" = atende (evidência formal de } \\
\text { implementação da prática indicada). }\end{array}$ \\
\hline $\begin{array}{l}1.2 \text { A aprovação das principais } \\
\text { políticas relacionados ao programa } \\
\text { de integridade é realizada pelas } \\
\text { mais elevadas instâncias decisórias } \\
\text { da organização? }\end{array}$ & $\begin{array}{l}\text { CGU (2015a, 2015b, 2017, 2018a, } \\
\text { 2018c); TCU (2014); Alliance for } \\
\text { Integrity (2015); Instituto Ethos } \\
\text { (2016, 2017); WBG (2010); LEC } \\
\text { Compliance (2017); US Department } \\
\text { of Justice (2019); Em pírica } \\
\text { Investimentos (2016); OCDE } \\
\text { (2018); Lei № 12.846/2013; Decreto } \\
\text { 5.450/05; Austin Rating (2013). }\end{array}$ & $\begin{array}{l}\text { Análise documental em manuais, } \\
\text { guias, planos e Programas de } \\
\text { Integridade, códigos de Ética e } \\
\text { Conduta, portarias e resoluções } \\
\text { que disciplinem a matéria. }\end{array}$ & $\begin{array}{l}\text { "0" = não atende (ausência de } \\
\text { disposição regulamentar e evidência } \\
\text { formal de implementação); } \\
\text { "1" = atende parcialmente (prática } \\
\text { prevista programaticamente, mas } \\
\text { até então não implementada OU } \\
\text { implementada parcialmente; } \\
\text { "2" = atende (evidência formal de } \\
\text { implementação da prática indicada). }\end{array}$ \\
\hline $\begin{array}{l}\text { 1.3 São emitidas manifestações } \\
\text { periódicas de apoio ao programa de } \\
\text { integridade assinadas diretamente } \\
\text { pela alta administração? }\end{array}$ & $\begin{array}{l}\text { CGU (2015a, 2015b, 2017, 2018a, } \\
\text { 2018c); TCU (2014); Alliance for } \\
\text { Integrity (2015); Instituto Ethos } \\
\text { (2016, 2017); WBG (2010); LEC } \\
\text { Compliance (2017); US Department } \\
\text { of Justice (2019); OCDE (2018); } \\
\text { Lei № 12.846/2013; Decreto } \\
\text { 5.450/05; Austin Rating (2013). }\end{array}$ & $\begin{array}{l}\text { Análise documental e m } \\
\text { comunicações oficiais, manuais, } \\
\text { guias, planos e Programas de } \\
\text { Integridade, códigos de Ética e } \\
\text { Conduta, portarias e resoluções } \\
\text { que disciplinem a matéria. }\end{array}$ & $\begin{array}{l}\text { "0" = não atende (ausência de } \\
\text { disposição regulamentar e evidência } \\
\text { formal de implementação); } \\
\text { "1" = atende parcialmente (prática } \\
\text { prevista programaticamente, mas } \\
\text { até então não implementada OU } \\
\text { implementada parcialmente; } \\
\text { "2" = atende (evidência formal de } \\
\text { implementação da prática indicada). }\end{array}$ \\
\hline $\begin{array}{l}1.4 \text { Há registros da participação } \\
\text { dos membros da alta gestão da } \\
\text { organização em treinamentos ou } \\
\text { capacitações sobre o programa de } \\
\text { integridade nos últimos } 12 \text { meses? }\end{array}$ & $\begin{array}{l}\text { CGU (2015a, 2015b, 2017, 2018a, } \\
\text { 2018c); TCU (2014); WBG (2010); } \\
\text { US Department of Justice (2019); } \\
\text { OCDE (2018); Lei № 12.846/2013; } \\
\text { Decreto 5.450/05. }\end{array}$ & $\begin{array}{l}\text { Análise documental em } \\
\text { relatórios de gestão, } \\
\text { comunicações oficiais, planos } \\
\text { de Integridade, portarias e } \\
\text { resoluções que disciplinem a } \\
\text { matéria. }\end{array}$ & $\begin{array}{l}\text { "0" = não atende (ausência de } \\
\text { disposição regulamentar e evidência } \\
\text { formal de implementação); } \\
\text { "1" = atende parcialmente (prática } \\
\text { prevista programaticamente, mas } \\
\text { até então não implementada OU } \\
\text { implementada parcialmente; } \\
\text { "2" = atende (evidência formal de } \\
\text { implementação da prática indicada). }\end{array}$ \\
\hline
\end{tabular}




\begin{tabular}{|c|c|c|c|}
\hline $\begin{array}{l}\text { 2. Gestão de Riscos } \\
\text { de Integridade }\end{array}$ & Referências & Fonte dos Dados & Classificação \\
\hline $\begin{array}{l}2.1 \text { Há registros da realização por } \\
\text { parte da organização de uma gestão } \\
\text { de riscos de integridade? }\end{array}$ & $\begin{array}{l}\text { IBGC (2015, 2018); CGU (2015a, } \\
\text { 2015b, 2017, 2018a, 2018b, } \\
\text { 2018c); TCU (2014); Alliance for } \\
\text { Integrity (2015); Instituto Ethos } \\
\text { (2016, 2017); WBG (2010); LEC } \\
\text { Compliance (2017, 2018); US } \\
\text { Department of Justice (2019); } \\
\text { Empírica Investimentos (2016); } \\
\text { USA (2018); OCDE (2018); } \\
\text { Lei No 12.846/2013; Decreto } \\
\text { 5.450/05; ABNT N R ISO } \\
\text { 31000:2009; COSO ERM (COSOII, } \\
\text { 2013); Austin Rating (2013). }\end{array}$ & $\begin{array}{l}\text { Análise documental em } \\
\text { relatórios de gestão, políticas } \\
\text { de governança e gestão de } \\
\text { riscos, manuais, guias, planos } \\
\text { e Programas de Integridade, } \\
\text { portarias e resoluções que } \\
\text { disciplinem a matéria. }\end{array}$ & $\begin{array}{l}\text { "0" = não atende (ausência de } \\
\text { disposição regulamentar e evidência } \\
\text { formal de implementação); } \\
\text { "1" = atende parcialmente (prática } \\
\text { prevista programaticamente, mas } \\
\text { até então não implementada OU } \\
\text { implementada parcialmente; } \\
\text { "2" = atende (evidência formal de } \\
\text { implementação da prática indicada). }\end{array}$ \\
\hline $\begin{array}{l}2.2 \text { A alta administração utiliza a } \\
\text { gestão de riscos para apoiar seus } \\
\text { processos decisórios? }\end{array}$ & $\begin{array}{l}\text { IBGC (2015, 2018); CGU (2015a, } \\
\text { 2015b, 2017, 2018a, 2018b, } \\
\text { 2018c); TCU (2014); Alliance for } \\
\text { Integrity (2015); Instituto Ethos } \\
\text { (2016, 2017); WBG (2010); LEC } \\
\text { Compliance (2017, 2018); US } \\
\text { Department of Justice (2019); } \\
\text { Empírica Investimentos (2016); USA } \\
\text { (2018); OCDE (2018); ABNT NBR ISO } \\
\text { 31000:2009; COSO ERM (COSO II, } \\
\text { 2013); Austin Rating (2013). }\end{array}$ & $\begin{array}{l}\text { Análise documental em } \\
\text { relatórios de gestão, políticas } \\
\text { de governança e gestão de } \\
\text { riscos, manuais, guias, planos } \\
\text { e Programas de Integridade, } \\
\text { portarias e resoluções que } \\
\text { disciplinem a matéria. }\end{array}$ & $\begin{array}{l}\text { "0" = não atende (ausência de } \\
\text { disposição regulamentar e evidência } \\
\text { formal de implementação); } \\
\text { "1" = atende parcialmente (prática } \\
\text { prevista programaticamente, mas } \\
\text { até então não implementada OU } \\
\text { implementada parcialmente; } \\
\text { "2" = atende (evidência formal de } \\
\text { implementação da prática indicada). }\end{array}$ \\
\hline $\begin{array}{l}\text { 2.3. Existem mecanismos } \\
\text { de controle que facilitem a } \\
\text { identificação e análise dos casos } \\
\text { suspeitos de má administração dos } \\
\text { recursos públicos, a partir da gestão } \\
\text { do orçamento e das contratações? }\end{array}$ & $\begin{array}{l}\text { IBGC (2015, 2018); CGU (2015a, } \\
\text { 2015b, 2017, 2018a, 2018b, } \\
\text { 2018c); TCU (2014); Alliance for } \\
\text { Integrity (2015); Instituto Ethos } \\
\text { (2016, 2017); WBG (2010); LEC } \\
\text { Compliance (2017, 2018); US } \\
\text { Department of Justice (2019); } \\
\text { Empírica Investimentos (2016); } \\
\text { USA (2018); Lei № 12.846/2013; } \\
\text { Decreto 5.450/05; OCDE (2018); } \\
\text { ABNT NBR ISO 31000:2009; } \\
\text { COSO ERM (COSO II, 2013); Austin } \\
\text { Rating (2013). }\end{array}$ & $\begin{array}{l}\text { Análise documental em relatórios } \\
\text { de gestão orçamentária, } \\
\text { políticas de governança e } \\
\text { gestão de riscos, manuais, } \\
\text { guias, planos e Programas de } \\
\text { Integridade, editais e contratos } \\
\text { administrativos, portarias e } \\
\text { resoluções que disciplinem a } \\
\text { matéria. }\end{array}$ & $\begin{array}{l}\text { "0" = não atende (ausência de } \\
\text { disposição regulamentar e evidência } \\
\text { formal de implementação); } \\
\text { "1" = atende parcialmente (prática } \\
\text { prevista programaticamente, mas } \\
\text { até então não implementada OU } \\
\text { implementada parcialmente; } \\
\text { "2" = atende (evidência formal de } \\
\text { implementação da prática indicada). }\end{array}$ \\
\hline $\begin{array}{l}\text { 2.4. Há registros de que os } \\
\text { protocolos de identificação, } \\
\text { avaliação e tratamento de riscos } \\
\text { de integridade foram realizados } \\
\text { nos últimos } 12 \text { meses? }\end{array}$ & $\begin{array}{l}\text { IBGC (2015, 2018); CGU (2015a, } \\
\text { 2015b, 2017, 2018a, 2018b, } \\
\text { 2018c); TCU (2014); Alliance for } \\
\text { Integrity (2015); Instituto Ethos } \\
\text { (2016, 2017); WBG (2010); LEC } \\
\text { Compliance (2017, 2018); US } \\
\text { Department of Justice (2019); } \\
\text { Empírica Investimentos (2016); } \\
\text { USA (2018); Lei № 12.846/2013; } \\
\text { Decreto 5.450/05; OCDE (2018); } \\
\text { ABNT NBR ISO 31000:2009; } \\
\text { COSO ERM (COSO II, 2013); Austin } \\
\text { Rating (2013). }\end{array}$ & $\begin{array}{l}\text { Análise documental em } \\
\text { relatórios de gestão, políticas } \\
\text { de governança e gestão de } \\
\text { riscos, manuais, guias, planos } \\
\text { e Programas de Integridade. }\end{array}$ & $\begin{array}{l}\text { "0" = não atende (ausência de } \\
\text { disposição regulamentar e evidência } \\
\text { formal de implementação); } \\
\text { "1" = atende parcialmente (prática } \\
\text { prevista programaticamente, mas } \\
\text { até então não implementada OU } \\
\text { implementada parcialmente; } \\
\text { "2" = atende (evidência formal de } \\
\text { implementação da prática indicada). }\end{array}$ \\
\hline
\end{tabular}


Continuação

\begin{tabular}{|c|c|c|c|}
\hline $\begin{array}{l}\text { 3. Código de Ética } \\
\text { e Conduta }\end{array}$ & Referências & Fonte dos Dados & Classificação \\
\hline $\begin{array}{l}\text { 3.1 A organização possui uma } \\
\text { Comissão de Ética formalmente } \\
\text { instituída? }\end{array}$ & $\begin{array}{l}\text { IBGC (2015, 2018); CGU (2015a, } \\
\text { 2015b, 2017, 2018a, 2018c); TCU } \\
\text { (2014); Alliance for Integrity (2015); } \\
\text { Instituto Ethos (2016, 2017); WBG } \\
\text { (2010); LEC Compliance (2017); Lei } \\
\text { № 12.846/2013; Decreto 5.450/05. }\end{array}$ & $\begin{array}{l}\text { Análise documental em códigos } \\
\text { de Ética e Conduta, manuais, } \\
\text { guias, planos e Programas } \\
\text { de Integridade, políticas } \\
\text { de governança, portarias } \\
\text { e resoluções que disciplinem } \\
\text { a matéria. }\end{array}$ & $\begin{array}{l}\text { "0" = não atende (ausência de } \\
\text { disposição regulamentar e evidência } \\
\text { formal de implementação); } \\
\text { "1" = atende parcialmente (prática } \\
\text { prevista programaticamente, mas } \\
\text { até então não implementada OU } \\
\text { implementada parcialmente; } \\
\text { "2" = atende (evidência formal de } \\
\text { implementação da prática indicada). }\end{array}$ \\
\hline $\begin{array}{l}\text { 3.2 Além dos normativos que } \\
\text { tratam da conduta ética do servidor, } \\
\text { a organização dispõe de Código de } \\
\text { Ética e Conduta de fácil acesso aos } \\
\text { empregados, contendo comandos } \\
\text { simples e diretos, e devidamente } \\
\text { aprovado pela alta gestão? }\end{array}$ & $\begin{array}{l}\text { IBGC (2015, 2018); CGU (2015a, } \\
\text { 2015b, 2017, 2018a, 2018c); TCU } \\
\text { (2014); Alliance for Integrity (2015); } \\
\text { Instituto Ethos (2016, 2017); WBG } \\
\text { (2010); LEC Compliance (2017); US } \\
\text { Department of Justice (2019); Lei } \\
\text { № 12.846/2013; Decreto 5.450/05. }\end{array}$ & $\begin{array}{l}\text { Análise documental em códigos } \\
\text { de Ética e Conduta, manuais, } \\
\text { guias, planos e Programas } \\
\text { de Integridade, portarias e } \\
\text { resoluções que disciplinem a } \\
\text { matéria e consulta a websites } \\
\text { oficiais. }\end{array}$ & $\begin{array}{l}\text { "0" = não atende (ausência de } \\
\text { disposição regulamentar e evidência } \\
\text { formal de implementação); } \\
\text { "1" = atende parcialmente (prática } \\
\text { prevista programaticamente, mas } \\
\text { até então não implementada OU } \\
\text { implementada parcialmente; } \\
\text { "2" = atende (evidência formal de } \\
\text { implementação da prática indicada). }\end{array}$ \\
\hline $\begin{array}{l}\text { 3.3 Se sim, o documento menciona } \\
\text { a possibilidade de aplicação } \\
\text { de sanções para aqueles que } \\
\text { cometerem violações éticas/legais, } \\
\text { independentemente do cargo ou } \\
\text { função ocupado pelo infrator? }\end{array}$ & $\begin{array}{l}\text { IBGC (2015, 2018); CGU (2015a, } \\
\text { 2015b, 2017, 2018a, 2018c); } \\
\text { TCU (2014); Alliance for Integrity } \\
\text { (2015); Instituto Ethos (2016, } \\
\text { 2017); LEC Compliance (2017); US } \\
\text { Department of Justice (2019); Lei } \\
\text { № 12.846/2013; Decreto 5.450/05. }\end{array}$ & $\begin{array}{l}\text { Análise documental em códigos } \\
\text { de Ética e Conduta, portarias } \\
\text { e resoluções que disciplinem } \\
\text { a matéria. }\end{array}$ & $\begin{array}{l}\text { "0" = não atende (ausência de } \\
\text { disposição regulamentar e evidência } \\
\text { formal de implementação); } \\
\text { "1" = atende parcialmente (prática } \\
\text { prevista programaticamente, mas } \\
\text { até então não implementada OU } \\
\text { implementada parcialmente; } \\
\text { "2" = atende (evidência formal de } \\
\text { implementação da prática indicada). }\end{array}$ \\
\hline $\begin{array}{l}\text { 3.4 Há registros de ações de } \\
\text { divulgação do Código de Ética e } \\
\text { Conduta, em canais internos e } \\
\text { externos, a fim de repassar seu } \\
\text { conteúdo a todos os servidores e } \\
\text { prestadores de serviço terceirizados } \\
\text { nos últimos } 12 \text { meses? }\end{array}$ & $\begin{array}{l}\text { IBGC (2015, 2018); CGU (2015a, } \\
\text { 2015b, 2017, 2018a, 2018c); TCU } \\
\text { (2014); Alliance for Integrity (2015); } \\
\text { Instituto Ethos (2016, 2017); } \\
\text { LEC Compliance (2017); Lei № } \\
\text { 12.846/2013; Decreto 5.450/05. }\end{array}$ & $\begin{array}{l}\text { Análise documental em } \\
\text { relatórios de gestão, } \\
\text { comunicações oficiais, códigos } \\
\text { de Ética e Conduta, manuais, } \\
\text { guias, planos e Programas } \\
\text { de Integridade, portarias e } \\
\text { resoluções que disciplinem a } \\
\text { matéria e consulta a websites } \\
\text { oficiais. }\end{array}$ & $\begin{array}{l}\text { "0" = não atende (ausência de } \\
\text { disposição regulamentar e evidência } \\
\text { formal de implementação); } \\
\text { "1" = atende parcialmente (prática } \\
\text { prevista programaticamente, mas } \\
\text { até então não implementada OU } \\
\text { implementada parcialmente; } \\
\text { "2" = atende (evidência formal de } \\
\text { implementação da prática indicada). }\end{array}$ \\
\hline
\end{tabular}




\begin{tabular}{|c|c|c|c|}
\hline $\begin{array}{l}\text { 4. Controles } \\
\text { Internos }\end{array}$ & Referências & Fonte dos Dados & Classificação \\
\hline $\begin{array}{l}4.1 \text { O órgão possui uma área de } \\
\text { auditoria interna formalmente } \\
\text { estruturada, com competências } \\
\text { claramente definidas, que se } \\
\text { reporte apenas à instância máxima } \\
\text { de governança da organização? }\end{array}$ & $\begin{array}{l}\text { IBGC (2015, 2018); CGU (2015a, } \\
\text { 2015b, 2017, 2018a, 2018c); TCU } \\
\text { (2014); Alliance for Integrity (2015); } \\
\text { Instituto Ethos (2016, 2017); WBG } \\
\text { (2010); LEC Compliance (2017); } \\
\text { US Department of Justice (2019); } \\
\text { Empírica Investimentos (2016); } \\
\text { USA (2018); OCDE (2018); Lei № } \\
\text { 12.846/2013; Decreto 5.450/05; } \\
\text { ABNT NBR ISO 31000:2009; } \\
\text { COSO ERM (COSO II, 2013); Austin } \\
\text { Rating (2013). }\end{array}$ & $\begin{array}{l}\text { Análise documental em } \\
\text { relatórios de gestão e políticas } \\
\text { de governança, manuais, } \\
\text { guias, planos e Programas } \\
\text { de Integridade, portarias e } \\
\text { resoluções que disciplinem a } \\
\text { matéria. }\end{array}$ & $\begin{array}{l}\text { "0" = não atende (ausência de } \\
\text { disposição regulamentar e evidência } \\
\text { formal de implementação); } \\
\text { "1" = atende parcialmente (prática } \\
\text { prevista programaticamente, mas } \\
\text { até então não implementada OU } \\
\text { implementada parcialmente; } \\
\text { "2" = atende (evidência formal de } \\
\text { implementação da prática indicada). }\end{array}$ \\
\hline $\begin{array}{l}4.2 \text { O órgão possui regras } \\
\text { que exigem a verificação do } \\
\text { cumprimento do objeto do contrato } \\
\text { para realização do pagamento? }\end{array}$ & $\begin{array}{l}\text { CGU (2015a, 2015b, 2017, 2018a, } \\
\text { 2018c); TCU (2014); USA (2018); Lei } \\
\text { № 12.846/2013; Decreto 5.450/05. }\end{array}$ & $\begin{array}{l}\text { Análise documental em } \\
\text { relatórios de auditoria e } \\
\text { gestão orçamentária, políticas } \\
\text { de governança, gestão de } \\
\text { riscos e controles, manuais, } \\
\text { guias, planos e Programas de } \\
\text { Integridade, editais e contratos } \\
\text { administrativos, portarias e } \\
\text { resoluções que disciplinem a } \\
\text { matéria. }\end{array}$ & $\begin{array}{l}\text { "0" = não atende (ausência de } \\
\text { disposição regulamentar eevidência } \\
\text { formal de implementação); } \\
\text { "1" = atende parcialmente (prática } \\
\text { prevista programaticamente, mas } \\
\text { até então não implementada OU } \\
\text { implementada parcialmente; } \\
\text { "2" = atende (evidência formal de } \\
\text { implementação da prática indicada). }\end{array}$ \\
\hline $\begin{array}{l}4.3 \text { O órgão possui regras que } \\
\text { estabelecem a segregação de } \\
\text { funções, de modo a não concentrar } \\
\text { o poder decisório em uma única } \\
\text { unidade? }\end{array}$ & $\begin{array}{l}\text { CGU (2015a, 2015b, 2017, 2018a, } \\
\text { 2018c); TCU (2014); USA (2018); Lei } \\
\text { № 12.846/2013; Decreto 5.450/05. }\end{array}$ & $\begin{array}{l}\text { Análise documental em } \\
\text { relatórios de auditorias e } \\
\text { gestão orçamentária, políticas } \\
\text { de governança, gestão de } \\
\text { riscos e controles, manuais, } \\
\text { guias, planos e Programas } \\
\text { de Integridade, portarias e } \\
\text { resoluções que disciplinem a } \\
\text { matéria. }\end{array}$ & $\begin{array}{l}\text { "0" = não atende (ausência de } \\
\text { disposição regulamentar e evidência } \\
\text { formal de implementação); } \\
\text { "1" = atende parcialmente (prática } \\
\text { prevista programaticamente, mas } \\
\text { até então não implementada OU } \\
\text { implementada parcialmente; } \\
\text { "2" = atende (evidência formal de } \\
\text { implementação da prática indicada). }\end{array}$ \\
\hline $\begin{array}{l}\text { 4.4 Os controles internos foram } \\
\text { revisados nos últimos } 12 \text { meses, } \\
\text { a fim de associá-los aos riscos aos } \\
\text { quais a organização está sujeita? }\end{array}$ & $\begin{array}{l}\text { IBGC (2015, 2018); CGU (2015a, } \\
\text { 2015b, 2017, 2018a, 2018c); TCU } \\
\text { (2014); Alliance for Integrity (2015); } \\
\text { Instituto Ethos (2016, 2017); WBG } \\
\text { (2010); LEC Compliance (2017); } \\
\text { US Department of Justice (2019); } \\
\text { Empírica Investimentos (2016); } \\
\text { USA (2018); OCDE (2018); Lei № } \\
\text { 12.846/2013; Decreto 5.450/05; } \\
\text { Austin Rating (2013). }\end{array}$ & $\begin{array}{l}\text { Análise documental em } \\
\text { relatórios de auditorias e } \\
\text { gestão orçamentária, políticas } \\
\text { de governança, gestão de } \\
\text { riscos e controles, manuais, } \\
\text { guias, planos e Programas } \\
\text { de Integridade, portarias e } \\
\text { resoluções que disciplinem a } \\
\text { matéria. }\end{array}$ & $\begin{array}{l}\text { "0" = não atende (ausência de } \\
\text { disposição regulamentar e evidência } \\
\text { formal de implementação); } \\
\text { "1" = atende parcialmente (prática } \\
\text { prevista programaticamente, mas } \\
\text { até então não implementada OU } \\
\text { implementada parcialmente; } \\
\text { "2" = atende (evidência formal de } \\
\text { implementação da prática indicada). }\end{array}$ \\
\hline
\end{tabular}


Continuação

\begin{tabular}{|c|c|c|c|}
\hline $\begin{array}{l}\text { 5. Treinamento } \\
\text { e Comunicação }\end{array}$ & Referências & Fonte dos Dados & Classificação \\
\hline $\begin{array}{l}5.1 \text { A organização dispõe de } \\
\text { planejamento para realização } \\
\text { de treinamentos e capacitações } \\
\text { relacionadas à promoção da ética } \\
\text { e integridade? }\end{array}$ & $\begin{array}{l}\text { IBGC (2015, 2018); CGU (2015a, } \\
\text { 2015b, 2017, 2018a, 2018c); TCU } \\
\text { (2014); Alliance for Integrity (2015); } \\
\text { Instituto Ethos (2016, 2017); WBG } \\
\text { (2010); LEC Compliance (2017); } \\
\text { US Department of Justice (2019); } \\
\text { Empírica Investimentos (2016); } \\
\text { USA (2018); OCDE (2018); Lei № } \\
\text { 12.846/2013; Decreto 5.450/05; } \\
\text { Austin Rating (2013). }\end{array}$ & $\begin{array}{l}\text { Análise documental em manuais, } \\
\text { guias, planos e Programas } \\
\text { de Integridade, políticas de } \\
\text { gestão de pessoas, portarias } \\
\text { e resoluções que disciplinem } \\
\text { a matéria. }\end{array}$ & $\begin{array}{l}\text { "0" = não atende (ausência de } \\
\text { disposição regulamentar eevidência } \\
\text { formal de implementação); } \\
\text { "1" = atende parcialmente (prática } \\
\text { prevista programaticamente, mas } \\
\text { até então não implementada OU } \\
\text { implementada parcialmente; } \\
\text { "2" = atende (evidência formal de } \\
\text { implementação da prática indicada). }\end{array}$ \\
\hline $\begin{array}{l}\text { 5.2 A instância responsável pelo } \\
\text { programa de integridade participa } \\
\text { do planejamento, elaboração, } \\
\text { aplicação e/ou contratação dos } \\
\text { treinamentos e capacitações sobre } \\
\text { temas de integridade? }\end{array}$ & $\begin{array}{l}\text { IBGC (2015, 2018); CGU (2015a, } \\
\text { 2015b, 2017, 2018a, 2018c); TCU } \\
\text { (2014); Alliance for Integrity (2015); } \\
\text { Instituto Ethos (2016, 2017); WBG } \\
\text { (2010); LEC Compliance (2017). }\end{array}$ & $\begin{array}{l}\text { Análise documental em manuais, } \\
\text { guias, planos e Programas } \\
\text { de Integridade, políticas de } \\
\text { gestão de pessoas, portarias } \\
\text { e resoluções que disciplinem } \\
\text { a matéria. }\end{array}$ & $\begin{array}{l}\text { "0" = não atende (ausência de } \\
\text { disposição regulamentar e evidência } \\
\text { formal de implementação); } \\
\text { "1" = atende parcialmente (prática } \\
\text { prevista programaticamente, mas } \\
\text { até então não implementada OU } \\
\text { implementada parcialmente; } \\
\text { "2" = atende (evidência formal de } \\
\text { implementação da prática indicada). }\end{array}$ \\
\hline $\begin{array}{l}5.3 \text { Os novos servidores } \\
\text { e empregados recebem } \\
\text { necessariamente capacitação } \\
\text { sobre ética e integridade no } \\
\text { serviço público antes de iniciar } \\
\text { suas funções? }\end{array}$ & $\begin{array}{l}\text { IBGC (2015, 2018); CGU (2015a, } \\
\text { 2015b, 2017, 2018a, 2018c); TCU } \\
\text { (2014); Instituto Ethos (2016, } \\
\text { 2017); LEC Compliance (2017). }\end{array}$ & $\begin{array}{l}\text { Análise documental em manuais, } \\
\text { guias, planos e Programas } \\
\text { de Integridade, políticas de } \\
\text { gestão de pessoas, portarias } \\
\text { e resoluções que disciplinem } \\
\text { a matéria. }\end{array}$ & $\begin{array}{l}\text { "0" = não atende (ausência de } \\
\text { disposição regulamentar e evidência } \\
\text { formal de implementação); } \\
\text { "1" = atende parcialmente (prática } \\
\text { prevista programaticamente, mas } \\
\text { até então não implementada OU } \\
\text { implementada parcialmente; } \\
\text { "2" = atende (evidência formal de } \\
\text { implementação da prática indicada). }\end{array}$ \\
\hline $\begin{array}{l}\text { 5.4 Foram adotas estratégias } \\
\text { para divulgar ostensivamente } \\
\text { e periodicamente os valores e } \\
\text { padrões de conduta adotados pela } \\
\text { organização nos últimos } 12 \text { meses? }\end{array}$ & $\begin{array}{l}\text { IBGC (2015, 2018); CGU (2015a, } \\
\text { 2015b, 2017, 2018a, 2018c); TCU } \\
\text { (2014); Instituto Ethos (2016, } \\
\text { 2017); LEC Compliance (2017). }\end{array}$ & $\begin{array}{l}\text { Análise documental em } \\
\text { comunicações oficiais, códigos } \\
\text { de Ética e Conduta, manuais, } \\
\text { guias, planos e Programas } \\
\text { de Integridade, políticas de } \\
\text { gestão de pessoas, portarias } \\
\text { e resoluções que disciplinem a } \\
\text { matéria e consulta a websites } \\
\text { oficiais. }\end{array}$ & $\begin{array}{l}\text { "0" = não atende (ausência de } \\
\text { disposição regulamentar e evidência } \\
\text { formal de implementação); } \\
\text { "1" = atende parcialmente (prática } \\
\text { prevista programaticamente, mas } \\
\text { até então não implementada OU } \\
\text { implementada parcialmente; } \\
\text { "2" = atende (evidência formal de } \\
\text { implementação da prática indicada). }\end{array}$ \\
\hline
\end{tabular}


Continuação

\begin{tabular}{|c|c|c|c|}
\hline $\begin{array}{l}\text { 6. Canais de Denúncia } \\
\text { (ouvidorias) }\end{array}$ & Referências & Fonte dos Dados & Classificação \\
\hline $\begin{array}{l}6.1 \text { O órgão disponibiliza canais } \\
\text { para realização de denúncias } \\
\text { (ouvidorias) tanto para os seus } \\
\text { empregados quanto para o público } \\
\text { em geral? }\end{array}$ & $\begin{array}{l}\text { IBGC (2015, 2018); CGU (2015a, } \\
\text { 2015b, 2017, 2018a, 2018c); TCU } \\
\text { (2014); Instituto Ethos (2016, } \\
\text { 2017); LEC Compliance (2017). }\end{array}$ & $\begin{array}{l}\text { Análise documental em planos } \\
\text { e Programas de Integridade } \\
\text { e consulta a websites oficiais } \\
\text { (e-OUV). }\end{array}$ & $\begin{array}{l}\text { "0" = não atende (ausência de } \\
\text { disposição regulamentar e evidência } \\
\text { formal de implementação); } \\
\text { "1" = atende parcialmente (prática } \\
\text { prevista programaticamente, mas } \\
\text { até então não implementada OU } \\
\text { implementada parcialmente; } \\
\text { "2" = atende (evidência formal de } \\
\text { implementação da prática indicada). }\end{array}$ \\
\hline $\begin{array}{l}6.2 \text { A organização presta } \\
\text { tratamento adequado a todo tipo } \\
\text { de manifestação, seja denúncia, } \\
\text { reclamação, elogio ou sugestão e } \\
\text { indica expressamente que os canais } \\
\text { de denúncia podem ser utilizados } \\
\text { para realização de denúncias } \\
\text { relacionadas à corrupção e demais } \\
\text { irregularidades? }\end{array}$ & $\begin{array}{l}\text { IBGC (2015, 2018); CGU (2015a, } \\
\text { 2015b, 2017, 2018a, 2018c); TCU } \\
\text { (2014); Instituto Ethos (2016, } \\
\text { 2017); LEC Compliance (2017). }\end{array}$ & $\begin{array}{l}\text { Análise documental em planos } \\
\text { e Programas de Integridade, } \\
\text { relatórios de gestão de } \\
\text { denúncias e consulta a websites } \\
\text { oficiais. }\end{array}$ & $\begin{array}{l}\text { "0" = não atende (ausência de } \\
\text { disposição regulamentar e evidência } \\
\text { formal de implementação); } \\
\text { "1" = atende parcialmente (prática } \\
\text { prevista programaticamente, mas } \\
\text { até então não implementada OU } \\
\text { implementada parcialmente; } \\
\text { "2" = atende (evidência formal de } \\
\text { implementação da prática indicada). }\end{array}$ \\
\hline $\begin{array}{l}6.3 \text { Os canais de denúncia } \\
\text { disponíveis indicam expressamente } \\
\text { as garantias de proteção oferecidas } \\
\text { aos denunciantes e possibilitam o } \\
\text { acompanhamento da apuração? }\end{array}$ & $\begin{array}{l}\text { IBGC (2015, 2018); CGU (2015a, } \\
\text { 2015b, 2017, 2018a, 2018c); TCU } \\
\text { (2014); Instituto Ethos (2016, } \\
\text { 2017); LEC Compliance (2017). }\end{array}$ & $\begin{array}{l}\text { Análise documental em planos } \\
\text { e Programas de Integridade } \\
\text { e consulta a websites oficiais } \\
\text { (e-OUV). }\end{array}$ & $\begin{array}{l}\text { "0" = não atende (ausência de } \\
\text { disposição regulamentar e evidência } \\
\text { formal de implementação); } \\
\text { "1" = atende parcialmente (prática } \\
\text { prevista programaticamente, mas } \\
\text { até então não implementada OU } \\
\text { implementada parcialmente; } \\
\text { "2" = atende (evidência formal de } \\
\text { implementação da prática indicada). }\end{array}$ \\
\hline $\begin{array}{l}\text { 6.4 Nos últimos } 12 \text { meses o órgão } \\
\text { realizou ações de divulgação dos } \\
\text { canais de denúncia? }\end{array}$ & $\begin{array}{l}\text { IBGC (2015, 2018); CGU (2015a, } \\
\text { 2015b, 2017, 2018a, 2018cb); } \\
\text { TCU (2014); Instituto Ethos (2016, } \\
\text { 2017); LEC Compliance (2017). }\end{array}$ & $\begin{array}{l}\text { Análise documental em } \\
\text { comunicações oficiais, planos } \\
\text { e Programas de Integridade, } \\
\text { políticas de gestão de denúncias } \\
\text { e consulta a websites oficiais. }\end{array}$ & $\begin{array}{l}\text { "0" = não atende (ausência de } \\
\text { disposição regulamentar e evidência } \\
\text { formal de implementação); } \\
\text { "1" = atende parcialmente (prática } \\
\text { prevista programaticamente, mas } \\
\text { até então não implementada OU } \\
\text { implementada parcialmente; } \\
\text { "2" = atende (evidência formal de } \\
\text { implementação da prática indicada). }\end{array}$ \\
\hline
\end{tabular}


Continuação

\begin{tabular}{|c|c|c|c|}
\hline $\begin{array}{l}\text { 7. Investigações } \\
\text { Internas }\end{array}$ & Referências & Fonte dos Dados & Classificação \\
\hline $\begin{array}{l}7.1 \text { A organização possui unidade } \\
\text { de correição (corregedoria) } \\
\text { instituída, cuja função precípua } \\
\text { seja a apuração de irregularidades } \\
\text { praticadas por agentes públicos } \\
\text { para aplicação de possíveis } \\
\text { sanções? }\end{array}$ & $\begin{array}{l}\text { IBGC (2015, 2018); CGU (2015a, } \\
\text { 2015b, 2017, 2018a, 2018c); TCU } \\
\text { (2014); Alliance for Integrity (2015); } \\
\text { Instituto Ethos (2016, 2017); WBG } \\
\text { (2010); LEC Compliance (2017); } \\
\text { US Department of Justice (2019); } \\
\text { Empírica Investimentos (2016); } \\
\text { USA (2018); OCDE (2018); Lei № } \\
\text { 12.846/2013; Decreto 5.450/05; } \\
\text { ABNT NBR ISO 31000:2009; } \\
\text { COSO ERM (COSO II, 2013); Austin } \\
\text { Rating (2013). }\end{array}$ & $\begin{array}{l}\text { Análise documental em políticas } \\
\text { de governança, relatórios de } \\
\text { investigações internas, manuais, } \\
\text { guias, planos e Programas } \\
\text { de Integridade, portarias e } \\
\text { resoluções que disciplinem a } \\
\text { matéria. }\end{array}$ & $\begin{array}{l}\text { "0" = não atende (ausência de } \\
\text { disposição regulamentar e evidência } \\
\text { formal de implementação); } \\
\text { "1" = atende parcialmente (prática } \\
\text { prevista programaticamente, mas } \\
\text { até então não implementada OU } \\
\text { implementada parcialmente; } \\
\text { "2" = atende (evidência formal de } \\
\text { implementação da prática indicada). }\end{array}$ \\
\hline $\begin{array}{l}7.2 \text { Os responsáveis pela aplicação } \\
\text { de sanções, seja a agentes públicos, } \\
\text { seja a pessoas jurídicas, são } \\
\text { devidamente capacitadas para } \\
\text { exercer essa função em específico? }\end{array}$ & $\begin{array}{l}\text { IBGC (2015, 2018); CGU (2015a, } \\
\text { 2015b, 2017, 2018a, 2018c); TCU } \\
\text { (2014); LEC Compliance (2017); } \\
\text { US Department of Justice (2019); } \\
\text { OCDE (2018). }\end{array}$ & $\begin{array}{l}\text { Análise documental em políticas } \\
\text { de governança e gestão de } \\
\text { pessoas, manuais, guias, planos } \\
\text { e Programas de Integridade, } \\
\text { portarias e resoluções que } \\
\text { disciplinem a matéria. }\end{array}$ & $\begin{array}{l}\text { "0" = não atende (ausência de } \\
\text { disposição regulamentar e evidência } \\
\text { formal de implementação); } \\
\text { "1" = atende parcialmente (prática } \\
\text { prevista programaticamente, mas } \\
\text { até então não implementada OU } \\
\text { implementada parcialmente; } \\
\text { "2" = atende (evidência formal de } \\
\text { implementação da prática indicada). }\end{array}$ \\
\hline $\begin{array}{l}\text { 7.3 As pessoas que compõem } \\
\text { a corregedoria participam dos } \\
\text { eventos promovidos pela Instância } \\
\text { de Integridade? }\end{array}$ & $\begin{array}{l}\text { IBGC (2015, 2018); CGU (2015a; } \\
\text { 2015b, 2017, 2018a, 2018c); TCU } \\
\text { (2014); Instituto Ethos (2016, } \\
\text { 2017); LEC Compliance (2017). }\end{array}$ & $\begin{array}{l}\text { Análise documental em políticas } \\
\text { de governança e gestão de } \\
\text { pessoas, manuais, guias, planos } \\
\text { e Programas de Integridade, } \\
\text { portarias e resoluções que } \\
\text { disciplinem a matéria. }\end{array}$ & $\begin{array}{l}\text { "0" = não atende (ausência de } \\
\text { disposição regulamentar e evidência } \\
\text { formal de implementação); } \\
\text { "1" = atende parcialmente (prática } \\
\text { prevista programaticamente, mas } \\
\text { até então não implementada OU } \\
\text { implementada parcialmente; } \\
\text { "2" = atende (evidência formal de } \\
\text { implementação da prática indicada). }\end{array}$ \\
\hline $\begin{array}{l}\text { 7.4 Há registros da execução de } \\
\text { ações de investigações internas no } \\
\text { âmbito da organização nos últimos } \\
12 \text { meses? }\end{array}$ & $\begin{array}{l}\text { IBGC (2015, 2018); CGU (2015a, } \\
\text { 2015b, 2017, 2018a, 2018c); TCU } \\
\text { (2014); Alliance for Integrity (2015); } \\
\text { Instituto Ethos (2016, 2017); WBG } \\
\text { (2010); LEC Compliance (2017); } \\
\text { US Department of Justice (2019); } \\
\text { Empírica Investimentos (2016); } \\
\text { USA (2018); OCDE (2018); Lei № } \\
\text { 12.846/2013; Decreto 5.450/05; } \\
\text { ABNT NBR ISO 31000:2009; } \\
\text { COSO ERM (COSO II, 2013); Austin } \\
\text { Rating (2013). }\end{array}$ & $\begin{array}{l}\text { Análise documental em políticas } \\
\text { de governança, relatórios de } \\
\text { investigações internas, planos } \\
\text { e Programas de Integridade, } \\
\text { portarias e resoluções que } \\
\text { disciplinem a matéria e consulta } \\
\text { a websites oficiais. }\end{array}$ & $\begin{array}{l}\text { "0" = não atende (ausência de } \\
\text { disposição regulamentar e evidência } \\
\text { formal de implementação); } \\
\text { "1" = atende parcialmente (prática } \\
\text { prevista programaticamente, mas } \\
\text { até então não implementada OU } \\
\text { implementada parcialmente; } \\
\text { "2" = atende (evidência formal de } \\
\text { implementação da prática indicada). }\end{array}$ \\
\hline
\end{tabular}




\begin{tabular}{|l|}
\hline \multicolumn{2}{|c|}{ 8. Due Diligence } \\
\hline 8.1 Nas minutas contratuais \\
há cláusula estabelecendo a \\
obrigatoriedade do cumprimento \\
de normas éticas e a vedação de \\
práticas de fraude e corrupção, \\
incluindo a previsão de \\
aplicação de penalidades e/ou \\
de rescisão contratual em caso \\
de descumprimento (cláusula \\
anticorrupção)?
\end{tabular}

8.20 órgão solicita que os terceiros contratados declarem expressamente estarem cientes da existência do Código de Ética ou Conduta da organização?

Referências
IBGC (2015, 2018); CGU (2015a,
2015b, 2017, 2018a, 2018c); TCU
(2014); Alliance for Integrity (2015);
Instituto Ethos (2016, 2017); WBG
(2010); US Department of Justice
(2019); Empírica Investimentos
(2016); USA (2018); OCDE (2018);
Lei No 12.846/2013; Decreto
5.450/05.
IBGC (2015, 2018); CGU (2015a,
2015b, 2017, 2018a, 2018c); TCU
(2014); Alliance for Integrity (2015);
Instituto Ethos (2016, 2017); WBG
(2010); LEC Compliance (2017);
US Department of Justice (2019);
Empírica Investimentos (2016);
USA (2018); OCDE (2018); Lei №
12.846/2013; Decreto 5.450/05;
Austin Rating (2013).

IBGC (2015, 2018); CGU (2015a, 2015b, 2017, 2018a, 2018c); TCU (2014); Alliance for Integrity (2015); Instituto Ethos (2016, 2017); WBG (2010); LEC Compliance (2017); US Department of Justice (2019); Empírica Investimentos (2016); USA (2018); OCDE (2018); Lei № 12.846/2013; Decreto 5.450/05; ABNT NBR ISO 31000:2009; COSO ERM (COSO II, 2013); Austin Rating (2013).

8.4 Nos últimos 12 meses foram estabelecidas e divulgadas regras claras e procedimentos no que diz respeito à integridade nas interações público-privadas é o relacionamento de agentes públicos com interessados, pessoas e instituições privadas?
IBGC (2015, 2018); CGU (2015a, 2015b, 2017, 2018a, 2018c); TCU (2014); Alliance for Integrity (2015); Instituto Ethos (2016, 2017); WBG (2010); LEC Compliance (2017); US Department of Justice (2019); Empírica Investimentos (2016); USA (2018); OCDE (2018); Lei № 12.846/2013; Decreto 5.450/05; ABNT NBR ISO 31000:2009; COSO ERM (COSO II, 2013); Austin Rating (2013).

Fonte dos Dados $\quad$ Classificação

Análise documental em "0" = não atende (ausência de planos e Programas de disposição regulamentar e evidência Integridade, editais e contratos formal de implementação); administrativos.

"1" = atende parcialmente (prática prevista programaticamente, mas até então não implementada OU implementada parcialmente; “2” = atende (evidência formal de implementação da prática indicada).

Análise documental em planos e Programas de Integridade, códigos de Ética e Conduta, editais, contratos administrativos, portarias e resoluções que disciplinem a matéria.

Análise documental em políticas de governança, gestão de riscos e controles, manuais, guias, planos e Programas de Integridade, editais e contratos administrativos, portarias e resoluções que disciplinem a matéria.

"0" = não atende (ausência de disposição regulamentar e evidência formal de implementação); "1" = atende parcialmente (prática prevista programaticamente, mas até então não implementada OU implementada parcialmente; " $\mathbf{2}$ " = atende (evidência formal de implementação da prática indicada).

" $\mathbf{0}^{\prime \prime}$ = não atende (ausência de disposição regulamentar e evidência formal de implementação); "1" = atende parcialmente (prática prevista programaticamente, mas até então não implementada OU implementada parcialmente; " $\mathbf{2}$ " = atende (evidência formal de implementação da prática indicada).

Análise documental em relatórios de gestão, políticas de governança, gestão de riscos e controles, manuais, guias, planos e Programas de Integridade, editais, contratos administrativos, portarias e resoluções que disciplinem a matéria.
"0" = não atende (ausência de disposição regulamentar e evidência formal de implementação); "1" = atende parcialmente (prática prevista programaticamente, mas até então não implementada OU implementada parcialmente; "2" = atende (evidência formal de implementação da prática indicada). 


\begin{tabular}{|c|c|c|c|}
\hline 9. Monitoramento & Referências & Fonte dos Dados & Classificação \\
\hline $\begin{array}{l}9.1 \text { O órgão possui uma instância } \\
\text { interna formalmente constituída } \\
\text { responsável exclusivamente pelo } \\
\text { programa de integridade? }\end{array}$ & $\begin{array}{l}\text { IBGC (2015, 2018); CGU (2015a, } \\
\text { 2015b, 2017, 2018a, 2018c); TCU } \\
\text { (2014); Alliance for Integrity (2015); } \\
\text { Instituto Ethos (2016, 2017); WBG } \\
\text { (2010); LEC Compliance (2017); } \\
\text { US Department of Justice (2019); } \\
\text { Empírica Investimentos (2016); } \\
\text { USA (2018); OCDE (2018); Lei № } \\
\text { 12.846/2013; Decreto 5.450/05; } \\
\text { Austin Rating (2013). }\end{array}$ & $\begin{array}{l}\text { Análise documental em políticas } \\
\text { de governança, manuais, } \\
\text { guias, planos e Programas } \\
\text { de Integridade, portarias e } \\
\text { resoluções que disciplinem a } \\
\text { matéria. }\end{array}$ & $\begin{array}{l}\text { "0" = não atende (ausência de } \\
\text { disposição regulamentar e evidência } \\
\text { formal de implementação); } \\
\text { "1" = atende parcialmente (prática } \\
\text { prevista programaticamente, mas } \\
\text { até então não implementada OU } \\
\text { implementada parcialmente; } \\
\text { "2" = atende (evidência formal de } \\
\text { implementação da prática indicada). }\end{array}$ \\
\hline $\begin{array}{l}\text { 9.2 Existem servidores dedicados } \\
\text { exclusivamente às atividades } \\
\text { relacionadas ao programa de } \\
\text { integridade dotados de garantias } \\
\text { expressas que possibilitam o } \\
\text { exercício das suas atribuições com } \\
\text { independência e autoridade? }\end{array}$ & $\begin{array}{l}\text { CGU (2015a, 2015b, 2017, 2018a, } \\
\text { 2018c); TCU (2014); Alliance for } \\
\text { Integrity (2015); Instituto Ethos } \\
\text { (2016, 2017); WBG (2010); LEC } \\
\text { Compliance (2017); US Department } \\
\text { of Justice (2019); Empírica } \\
\text { Investimentos (2016); USA (2018); } \\
\text { OCDE (2018); Lei No 12.846/2013; } \\
\text { Decreto 5.450/05; Austin Rating } \\
\text { (2013). }\end{array}$ & $\begin{array}{l}\text { Análise documental em políticas } \\
\text { de governança, manuais, } \\
\text { guias, planos e Programas } \\
\text { de Integridade, portarias e } \\
\text { resoluções que disciplinem a } \\
\text { matéria. }\end{array}$ & $\begin{array}{l}\text { "0" = não atende (ausência de } \\
\text { disposição regulamentar e evidência } \\
\text { formal de implementação); } \\
\text { "1" = atende parcialmente (prática } \\
\text { prevista programaticamente, mas } \\
\text { até então não implementada OU } \\
\text { implementada parcialmente; } \\
\text { "2" = atende (evidência formal de } \\
\text { implementação da prática indicada). }\end{array}$ \\
\hline $\begin{array}{l}9.3 \text { O responsável pela instância } \\
\text { interna possui como prerrogativa } \\
\text { a possibilidade de se reportar } \\
\text { diretamente ao nível hierárquico } \\
\text { mais elevado da organização? }\end{array}$ & $\begin{array}{l}\text { CGU (2015a, 2015b, 2017, 2018a, } \\
\text { 2018c); TCU (2014); Alliance for } \\
\text { Integrity (2015); Instituto Ethos } \\
\text { (2016, 2017); WBG (2010); LEC } \\
\text { Compliance (2017); US Department } \\
\text { of Justice (2019); USA (2018); } \\
\text { OCDE (2018); Lei № 12.846/2013; } \\
\text { Decreto 5.450/05. }\end{array}$ & $\begin{array}{l}\text { Análise documental em políticas } \\
\text { de governança, manuais, } \\
\text { guias, planos e Programas } \\
\text { de Integridade, portarias e } \\
\text { resoluções que disciplinem a } \\
\text { matéria. }\end{array}$ & $\begin{array}{l}\text { "0" = não atende (ausência de } \\
\text { disposição regulamentar e evidência } \\
\text { formal de implementação); } \\
\text { "1" = atende parcialmente (prática } \\
\text { prevista programaticamente, mas } \\
\text { até então não implementada OU } \\
\text { implementada parcialmente; } \\
\text { "2" = atende (evidência formal de } \\
\text { implementação da prática indicada). }\end{array}$ \\
\hline $\begin{array}{l}\text { 9.4 Há registros de execução } \\
\text { de ações de monitoramento do } \\
\text { Programa de Integridade, a fim de } \\
\text { adequar seus instrumentos a novos } \\
\text { cenários eatores de forma a reforçar } \\
\text { a resiliência da organização a } \\
\text { atos de corrupção, nos últimos } \\
12 \text { meses? }\end{array}$ & $\begin{array}{l}\text { IBGC (2015, 2018); CGU (2015a, } \\
\text { 2015b, 2017, 2018a, 2018c); TCU } \\
\text { (2014); Alliance for Integrity (2015); } \\
\text { Instituto Ethos (2016, 2017); WBG } \\
\text { (2010); LEC Compliance (2017); } \\
\text { US Department of Justice (2019); } \\
\text { Empírica Investimentos (2016); } \\
\text { USA (2018); OCDE (2018); Lei № } \\
\text { 12.846/2013; Decreto 5.450/05; } \\
\text { Austin Rating (2013). }\end{array}$ & $\begin{array}{l}\text { Análise documental em políticas } \\
\text { de governança, relatórios de } \\
\text { gestão de Integridade, manuais, } \\
\text { guias, planos e Programas } \\
\text { de Integridade, portarias e } \\
\text { resoluções que disciplinem a } \\
\text { matéria. }\end{array}$ & $\begin{array}{l}\text { "0" = não atende (ausência de } \\
\text { disposição regulamentar e evidência } \\
\text { formal de implementação); } \\
\text { "1" = atende parcialmente (prática } \\
\text { prevista programaticamente, mas } \\
\text { até então não implementada OU } \\
\text { implementada parcialmente; } \\
\text { "2" = atende (evidência formal de } \\
\text { implementação da prática indicada). }\end{array}$ \\
\hline
\end{tabular}

Fonte: Elaborado pelos autores. 